Article

\title{
Development of Acoustic Emission Sensor Optimized for Partial Discharge Monitoring in Power Transformers
}

\author{
Wojciech Sikorski \\ Institute of Electrical Power Engineering, Poznan University of Technology, Piotrowo 3A, 60-965 Poznan, Poland; \\ wojciech.sikorski@put.poznan.pl
}

Received: 29 March 2019; Accepted: 16 April 2019; Published: 18 April 2019

check for updates

\begin{abstract}
The acoustic emission (AE) technique is one of the unconventional methods of partial discharges (PD) detection. It plays a particularly important role in oil-filled power transformers diagnostics because it enables the detection and online monitoring of PDs as well as localization of their sources. The performance of this technique highly depends on measurement system configuration but mostly on the type of applied AE sensor. The paper presents, in detail, the design and manufacturing stages of an ultrasensitive AE sensor optimized for partial discharge detection in power transformers. The design assumptions were formulated based on extensive laboratory research, which allowed for the identification of dominant acoustic frequencies emitted by partial discharges in oil-paper insulation. The Krimholtz-Leedom-Matthaei (KLM) model was used to iteratively find optimal material and geometric properties of the main structures of the prototype AE sensor. It has two sensing elements with opposite polarization direction and different heights. The fully differential design allowed to obtain the desired properties of the transducer, i.e., a two-resonant $(68 \mathrm{kHz}$ and

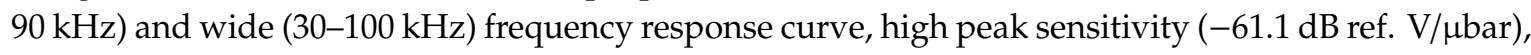
and low noise. The laboratory tests confirmed that the prototype transducer is characterized by ultrahigh sensitivity of partial discharge detection. Compared to commonly used commercial AE sensors, the average amplitude of PD pulses registered with the prototype sensor was a minimum of $5.2 \mathrm{~dB}$ higher, and a maximum of $19.8 \mathrm{~dB}$ higher.
\end{abstract}

Keywords: acoustic emission (AE); ultrasonic transducer; partial discharge (PD); surface discharge; interturn discharge; oil-paper insulation; power transformer diagnostics; KLM model

\section{Introduction}

Power transformers are a strategic component of the electric power system. It is commonly believed that the oil-paper insulation system is designed in order to work reliably for 30-40 years. However, there are many power transformers installed all around the world, which operate without failure above this age. The asset management strategy developed by most power distribution companies, which is directed towards an extension of transformer life, results mostly from the high cost of the device purchased as well as long delivery time, reaching over a year. However, such policy increases the probability of catastrophic failure occurrence, which is followed by a number of negative consequences, such as a threat to the life of the substation staff, significant economic losses, environmental hazards (oil leaks or fire), and local blackouts [1-5]. Therefore, recently, an increase of requirements towards the reliability of the exploited power transformers and the demand for professional services and diagnostics solutions has been observed. Such a strategy extends the time of safe exploitation of older units [6-10]. While analyzing cases of power transformer breakdowns described in the literature or reports of power distribution companies, one may notice that many of them are related to accelerated 
degradation of the insulation system, which might have been caused by the high activity of partial discharges [1,11-14]. For that reason, monitoring of PD intensity and the dynamics of its changes may be an important indicator to predict impending failure. The effectiveness of PD detection depends not only on the applied measurement technique, but also on the configuration of the measurement system, particularly on PD sensors performance. The highest sensitivity of PD pulse detection may be obtained using a measurement setup that complies with the IEC 60270 standard (so-called conventional electrical method) $[15,16]$. Under ideal measuring conditions (shielded high-voltage laboratory), the conventional electrical method allows detection of low-energy PD pulses (apparent charge $<0.1 \mathrm{pC}$ ). Unfortunately, PD detection in field conditions, due to the high level of electromagnetic disturbances (switching operations and corona discharge in transmission lines), is practically impossible [17]. Mainly for that reason, online monitoring systems available on the market or currently developed by research centers are based only on unconventional PD detection methods. This group includes dissolved gas analysis (DGA) in oil [18-20], detection of electromagnetic waves in the high-frequency (HF) [21,22] and ultrahigh frequency (UHF) ranges [23-27], and the acoustic emission method (AE), which, apart from detection and on-line monitoring of PD, also locates PD sources [28-32]. It should be underlined that sensitivity of these techniques highly depends on sensor position in a power transformer tank and its distance from the PD source as well as on the construction and parameters of the sensor [33].

In the acoustic emission method, mostly piezoelectric contact transducers are used for PD detection. It should be noted that in the last few years the research works on alternative solutions have been conducted. Sikorski in [34] presented an active dielectric window (ADW). It is a new concept of combined acoustic emission (AE) and electromagnetic PD detector intended for assembly in the transformer's inspection hatch. A similar approach was presented by Siegel et al. [35], but, in this case, a sensor able to detect AE and UHF signals was mounted through an oil drain valve. Due to the high cost of commercial AE sensors, some researchers propose low-budget solutions, based on, among others, the application of piezoelectric diaphragms (buzzers) [36].

Leading manufacturers, like Physical Acoustics or Vallen Systeme, offer several dozen different types of piezoelectric sensors, which cover the demand of the majority of research fields and diagnostic techniques based on the acoustic emission phenomenon. Depending on application type and, resulting from it, the frequencies of ultrasonic signals registered, transducers are divided into three categories: low frequency $(20-100 \mathrm{kHz})$, standard frequency $(100-400 \mathrm{kHz})$, and high frequency ( $>400 \mathrm{kHz}$ ) sensors. The category of standard frequency sensors is the most numerous. They are, among others, used for drying process monitoring of wood, hot reheat pipe crack detection, or integrity testing of pressure vessels, metallic, and composite structures. Low-frequency AE sensors are usually recommended for structural health monitoring of large concrete and geologic structures, leakage detection in liquid pipelines, and corrosion screening of flat bottom storage tanks. In turn, high-frequency sensors are applied in AE testing of small specimens $[37,38]$. Wideband AE sensors with a flat frequency response curve (at the cost of less sensitivity) are a separate category. Despite lower efficiency, this type of transducers is ideal in cases where the frequency of $\mathrm{AE}$ signals generated by the investigated phenomenon is unknown or when acquired AE signals are broadband by nature.

The recommendations of the leading manufacturers regarding the optimal choice of sensor for PD detection in oil-filled transformers are far less unambiguous than in case of the remaining $\mathrm{AE}$ applications. Vallen Systeme suggests the use of a transducer operating in the range between $100 \mathrm{kHz}$ and $400 \mathrm{kHz}$ or low-frequency transducer $(20-100 \mathrm{kHz})$ when noise is low. From the variety of the offered several dozens of sensors, the producer selected two models for PD detection, i.e., VS30 (20-80 kHz) and VS75 (30-120 kHz, frequency peak $75 \mathrm{kHz})$ [38]. In turn, Physical Acoustics offered five models of transducers (D9241A, R6D, R15D, R30D, and R50D), for which monitoring of large power transformers is specified as one of the typical applications [39]. Providing such sensors is quite confusing since they work in different frequency ranges. For instance, the operating frequency range for sensor type D9241A is from $20 \mathrm{kHz}$ to $60 \mathrm{kHz}$ (with frequency peak $30 \mathrm{kHz}$ ) and for sensor 
type R15D from $50 \mathrm{kHz}$ to $400 \mathrm{kHz}$ (resonant frequencies: $75 \mathrm{kHz}$ and $150 \mathrm{kHz}$ ), whereas for sensor type R50D between $100 \mathrm{kHz}$ and $700 \mathrm{kHz}$ (resonant frequencies: $100 \mathrm{kHz}$ and $500 \mathrm{kHz}$ ) [39].

The presented information show that, so far, the manufacturers have not elaborated an AE sensor specially designed and optimized for PD detection in oil-filled power transformers. It is hard to blame only the producers because there are at least several reasons for such a situation. First, power transformer diagnostics using the AE method are still being run on a fairly small scale, particularly compared to such industrial applications of the AE method such as structural health monitoring of large concrete and steel structures, fatigue and fracture materials research, bearing condition monitoring, or leakage detection in pipelines. Second, scientists investigating AE signals emitted by PD—depending on the type of the applied ultrasonic transducer and measurement set-up configuration-draw quite different conclusions (see details in Section 2). Third, recommendations included in official documents of international organizations establishing standards (IEC, IEEE, and CIGRE) are very general. In the Guide for the Detection of Acoustic Emissions from Partial Discharges in Oil-Immersed Power Transformers issued by IEEE in 2000 [40], the AE sensor for PD detection is defined as a piezoelectric displacement transducer operating in its compression mode and has a resonant frequency (for longitudinal waves) in the 120 to $160 \mathrm{kHz}$ range. Users are recommended to apply a band-pass filter (with lower and upper cutoff frequencies of $100 \mathrm{kHz}$ and $300 \mathrm{kHz}$ ) to eliminate most of the signals that are not associated with PDs, e.g., vibrations caused by the magnetostrictive action of the core (Barkhausen noise), oil pumps, and cooling fans. Simultaneously, it was noted that depending on location and type of PD source, some group of users find that a low-frequency AE sensor (e.g., $60 \mathrm{kHz}$ ) is more useful, particularly when higher-frequency signals are attenuated. However, the IEEE guide criticizes this type of sensor for being more susceptible to external or other mechanical signals.

In the revised version of the IEEE C57.127 guide issued seven years later, more attention was paid to the problem of the adequate sensor selection [41]. First of all, it was highlighted that the main frequency of low-energy PDs (e.g., partial discharge in oil and PD in voids or gas bubbles) is $100 \mathrm{kHz}$ and for larger discharges (surface discharges, turn-to-turn discharges, and arcing) frequencies should decrease (20-100 kHz). Furthermore, the low-frequency AE waves are less attenuated. For that reason, part of the users-particularly for factory and laboratory applications-choose sensors with resonant frequencies for longitudinal waves of $60 \mathrm{kHz}$. However, fearing of external disturbances and noises occurring in the band between $20 \mathrm{kHz}$ and even $60 \mathrm{kHz}$, most users apply sensors with the resonant frequency of $150 \mathrm{kHz}$. Unfortunately, this choice is not related to the partial discharges frequency at all. Rather, this is due to the fact that $150 \mathrm{kHz}$ standard transducers are easy available on the market (e.g., Physical Acoustics R15 $\alpha$ and R15D, Vallen VS150, Soundwel SR150, Bangos AES150, Acoustic Emission Consulting i150, Fuji Ceramics AE154DL, AE144S, etc.). The $150 \mathrm{kHz}$ standard AE sensor may reduce the noise level compared to the $60 \mathrm{kHz}$ resonant frequency sensor, but it will also strongly reduce PD detection sensitivity [41,42].

In 2009 CIGRE Working Group D1.33 published a technical brochure titled Guidelines for Unconventional Partial Discharge Measurements [43], in which one may find information that PD occurrence is a source of acoustic emission signals of frequencies in a band between $10 \mathrm{kHz}$ and $300 \mathrm{kHz}$. In turn, in a brochure issued in 2015 titled Guidelines for Partial Discharge Detection using Conventional (IEC 60270) and Unconventional Methods [44], according to the CIGRÉ Working Group D1.37 experts, the frequency band of the AE signals emitted by PDs is definitely wider and is in the range from 20 to even $1000 \mathrm{kHz}$. The change in recommendations might have been caused by the fact that part of the researchers prefers broadband multiresonant transducers.

In the standard IEC TS 62478: High voltage test techniques-Measurement of partial discharges by electromagnetic and acoustic methods published in 2016 by the International Electrotechnical Commission (IEC) — the detailed guidelines regarding AE sensors were not included [45]. The document informs that for PD detection, typically the ultrasonic frequency range is employed (approximately $20 \mathrm{kHz}$ to $250 \mathrm{kHz}$ ), as well as the audible range (approximately $100 \mathrm{~Hz}$ to $20 \mathrm{kHz}$ ). It additionally 
underlines that the frequency ranges used for acoustic detection are chosen depending on the insulation system (solid, liquid, or gaseous), for which the AE method is being employed.

The newest document, in which the issue of AE sensor selection has been raised, is a brochure Partial Discharges in Transformers elaborated by CIGRÉ Working Group D1.29 and issued in February 2017 [46]. This document suggests using transducers working in a band of 10 to $300 \mathrm{kHz}$, where in order to obtain the highest PD detection sensitivity, resonant type piezoelectric sensors with resonance frequency between $60 \mathrm{kHz}$ and $150 \mathrm{kHz}$ are recommended.

The relatively low PD detection sensitivity of the AE method used in power transformers diagnostics is considered as one of its main disadvantages. This results directly from the physical nature of the PD phenomenon because only a small part of the energy of a PD current pulse is transformed into mechanical energy in the form of acoustic waves. Another reason is the AE wave attenuation-the combined effect of scattering, absorption, and reflection of sound waves, which occurs on the wave propagation path between PD source and the ultrasonic transducer. Therefore, the use of a proper ultrasonic transducer is so important from the AE method efficiency point of view [33].

The above-presented state of affairs has become a motivation to design and manufacture an $\mathrm{AE}$ sensor optimized for detection and monitoring of PD in oil-filled power transformers. As a result of the conducted research, a prototype ultrasonic transducer was developed, which sensitivity of partial discharges detection is higher than in the case of the most popular commercial AE sensors. In addition, its most important advantage is its very simple structure and low production costs. The prototype sensor presented in this article may find application in the AE systems specially designed for locating or online monitoring of partial discharges in large power transformers. In the theoretical part of the manuscript (Section 2), the results of the previous works on acoustic frequencies emitted by partial discharges in oil-paper insulation were discussed. The investigated types of PDs and electrode systems used in the experiment were described in Section 3. Parameters of the measurement setup, in which the frequencies of AE signals generated by partial discharges, were identified were presented in Section 4 . Basing on the obtained measurement results (Section 5), a prototype AE sensor was designed and manufactured. The details concerning this task were discussed in Section 6. Finally, the prototype sensor was tested, in order to evaluate its performance compared to commonly used commercial AE sensors (Section 7).

\section{Acoustic Frequencies Emitted by Partial Discharges in Oil-Paper Insulation-Previous Works}

One of the first papers dealing with the frequency analysis of AE signals emitted by partial discharges in oil-paper insulation was presented by R.T. Harrold in 1975 [47]. Ultrasonic signals were recorded using a wideband transducer, which was composed of a lithium sulfate disc $(0.147 \mathrm{~cm}$ thick, $2.28 \mathrm{~cm}$ diameter) with stainless-steel electrodes. In his research, the author limited the analyzed frequency band to the range from $150 \mathrm{kHz}$ to $1.75 \mathrm{MHz}$. On the basis of the obtained results, the following conclusions were formulated. (1) Ultrasonic frequency spectra from $150 \mathrm{kHz}$ to $1.75 \mathrm{MHz}$ emitted by different types of PD in oil had not revealed any unique frequency of high acoustic energy; (2) using resonant transducers in the band above $150 \mathrm{kHz}, \mathrm{AE}$ from various PD sources should easily be detected, but signals received at the lower frequencies were higher and the frequency spectrum of a point-to-pressboard plane source in oil might have cut off near $300 \mathrm{kHz}$; and (3) detection of PD sources using acoustic emission technique was more readily achieved using resonant transducers operating in the $20 \mathrm{kHz}$ to $100 \mathrm{kHz}$ range.

In another of Harrold's works [48], the acoustic emission signal generated by sparks and arcs in mineral oil was investigated. Partial discharge pulses were recorded with both narrowband and wideband ultrasonic transducers: Brüel \& Kjaer type 4135 condenser microphone $(10 \mathrm{~Hz}-100 \mathrm{kHz})$, Brüel \& Kjaer type 4131 condenser microphone $(20 \mathrm{~Hz}-20 \mathrm{kHz})$, Celesco type LC-10 hydrophone $(1 \mathrm{kHz}-100 \mathrm{kHz})$, self-produced wideband hydrophone $(1 \mathrm{kHz}-2 \mathrm{MHz})$, and Physical Acoustics Corporation contact microphone, type 15-12 (up to $500 \mathrm{kHz}$ ). Studies showed that (as previously theoretically predicted), high energy (kJ) arcs radiate maximum acoustic levels in the low frequency 
region from $\sim 120 \mathrm{~Hz}$ to $\sim 10 \mathrm{kHz}$, whereas, low energy ( $\mu \mathrm{J}$ ) PD (microsparks) have maximum acoustic emission at higher frequencies in the $\sim 10 \mathrm{kHz}$ to $\sim 400 \mathrm{kHz}$ range.

Howells and Norton [49] were one of the first to publish a comprehensive report, in which they assessed the possibility of practical application of the AE method for diagnostics of power transformers. The authors performed laboratory tests on three small distribution $10 \mathrm{kVA}$ transformers with deliberately modeled defects to generate and register AE pulses from partial discharges. The applied AE measurement system consisted of a piezoelectric resonant-type transducer (Dunegan S140 L/D with $140 \mathrm{kHz}$ nominal resonant frequency) and $100 \mathrm{kHz}$ high-pass filter. Such configuration strongly influenced the frequency parameters of the registered AE pulses. Their dominant frequency $(\sim 150 \mathrm{kHz})$ practically coincided with the resonance frequency of the ultrasonic transducer. The authors also presented the results obtained during the induced voltage tests with PD measurement of two large power transformers ( $230 \mathrm{kV} / 56 \mathrm{MVA}$ and $230 \mathrm{kV} / 200 \mathrm{MVA})$. The same type of ultrasonic transducer was used to detect AE pulses, but this time the high-pass filter with a lower cutoff frequency $(20 \mathrm{kHz}$ instead of $100 \mathrm{kHz}$ ) was used. For both tested transformers, AE pulses were recorded only at higher voltage levels (130\% and $150 \%$ rated voltage, respectively). The frequency-domain analysis showed that most of the AE signal energy from PD is transmitted in the low-frequency band (from $20 \mathrm{kHz}$ to about $80 \mathrm{kHz}$ ), and the rest in the range of 140 to $170 \mathrm{kHz}$, that is close to the resonant frequency of the transducer.

In the work of Zhu et al. [50], the relations between various types of PD in the transformer and their frequency spectra of AE were studied. For this purpose, different electrode systems were used, in which insulation defects were modeled: (1) PD of protrusions in transformer; (2) PD of point electrode with different curvature; (3) PD along barrier surface in transformer; (4) PD in gaseous void in solid insulation of transformer; and (5) PD in the thick paper insulation of high voltage connection of transformer. Furthermore, the authors investigated the frequency of acoustic signals generated by magnetic noises. In this study, two kinds of AE sensor with piezoelectric elements were used. One was wideband and the other narrowband. Their maximum frequency response was $700 \mathrm{kHz}$ and $200 \mathrm{kHz}$, respectively. Based on the obtained results, the following conclusions were drawn. (1) Obtained peak frequencies in the frequency spectra of AE from PD distributed within 70 to $150 \mathrm{kHz}$; (2) frequency spectra analysis showed that frequencies of Barkhaussen noise were lower than $20 \mathrm{kHz}$ and frequencies of magneto-mechanical AE were within $20-65 \mathrm{kHz}$; (3) to minimize the negative impact of magnetic noises, frequency bandwidth of $70-180 \mathrm{kHz}$ was recommended for the AE measuring system of PD detection in power transformer; and (4) various types of PD emit signals of different frequencies, which made it possible to identify insulation defects.

Bengtsson et al. [51] performed a transducer independent determination of the acoustic frequencies emitted by a partial discharge in oil. For this purpose, the experiment was based on the phenomenon of single-slit diffraction, and the registration of AE pulses was performed using two $100 \mathrm{kHz}$ hydrophones. The first one was a reference and the second one was mounted in a computer controlled moving frame. It was found that the main signal content from low-energy PDs $\sim 100 \mathrm{pC}$ magnitude is $\sim 100 \mathrm{kHz}$ (91 kHz and $99 \mathrm{kHz}$ are peak frequencies). In the later publication [42], the authors stated that due to the short AE signal duration, the frequency distribution was rather wide. However, due to the effect that high-frequency components are strongly attenuated by pressboard, they prefer acoustic sensors in the 20 to $120 \mathrm{kHz}$ range, which is lower than recommended by users, who are afraid of core noises. The authors also presented interesting results of the experiment, in which PDs in the insulation of a paper-wound conductor were recorded simultaneously using low and high-frequency sensors. This experiment shows that the detection sensitivity for this type of PD signals is higher using low-frequency sensors (peak frequency was $\sim 50 \mathrm{kHz}$ ) as the high-frequency components are severely attenuated.

In another Bengtsson paper [52], for recording PD pulses in transformer oil, the UAEA 250 transducer with two resonant frequencies- $125 \mathrm{kHz}$ and $250 \mathrm{kHz}$ - was used. In the point-to-plate electrode system immersed in oil, the main frequency of registered AE signals overlapped with the first 
resonance frequency of the UAEA transducer $(125 \mathrm{kHz})$. In turn, in the case of creeping discharges, most of the energy of the AE signal was transmitted in the low-frequency range from approximately 25 to $40 \mathrm{kHz}$ and close to the center frequency of the transducer $(110-130 \mathrm{kHz})$.

In research carried out by Sakoda et al. [53], ultrasonic waves caused by a single PD pulse in oil were measured. The results of these measurements were analyzed by means of an FFT in order to understand the properties of the elastic waves and distinguish the kinds of detectable elastic waves. Broadband ultrasonic transducer $(1000 \mathrm{kHz})$ was used in the research. The results presented in the paper proved that almost all energy of AE pulses from $\mathrm{PD}$ in oil was transmitted in the lower frequency band (up to about $100 \mathrm{kHz}$ ) and the dominant frequency was about $25 \mathrm{kHz}$.

In turn, Boczar [54] analyzed the AE signals emitted by (1) surface discharges in oil, (2) gas bubble discharges in oil, and (3) discharges in indeterminate potential particles moving in oil. Detection of $\mathrm{AE}$ pulses was performed by a wideband (from $10 \mathrm{kHz}$ to $1 \mathrm{MHz}$ ) piezoelectric transducer type 8312 of Brüel \& Kjaer, with a standard $40 \mathrm{~dB}$ built-in preamplifier. The creeping discharges generated low-frequency AE signals (below $100 \mathrm{kHz}$ ), with most of the energy being carried in the band from about 70 to $90 \mathrm{kHz}$. The other two types of PD generated signals in a much wider frequency band.

Kundu et al. [55] studied PD on conductor protrusions in the transformer and PD along barrier surface in the transformer. Point-to-plane electrode systems were used to model the PD on protrusions, plane-to-plane electrodes with pressboard insulation and rod-to-plane electrodes with pressboard insulation were used to model surface discharge. The resonance-type $150 \mathrm{kHz}$ AE sensor was used to acquire PD signals. For the PD in oil, the average peak frequency was $128 \mathrm{kHz}$ and the median frequency was $138 \mathrm{kHz}$. AE signals from surface discharges had definitely lower frequencies. In a plane-to-plane electrode system, the average peak frequency of $\mathrm{AE}$ was $60 \mathrm{kHz}$ and in rod-to-plane electrode system configuration was $50 \mathrm{kHz}$. The average of median frequency was $78 \mathrm{kHz}$ and $88 \mathrm{kHz}$, respectively.

In the work of Sikorski [56], most of the basic types of partial discharges (ten types in total) occurring in oil-paper insulation were examined. Based on the results of the research, the following conclusions were formulated. (1) Each of the investigated PD forms generates repeatable and unique AE signals, (2) results of frequency-domain analysis strongly depend on the type of the applied sensor, (3) the low-frequency $(30 \mathrm{kHz})$ sensor is more sensitive in detection of high-energy PD like surface discharges than wideband sensor, (4) high-energy creeping sparks generate AE signal in the 20 to $40 \mathrm{kHz}$ frequency band, and (5) low-energy PD, like discharges in gas bubbles or in internal gas voids, emit short AE pulses in the higher frequency band (100-300 kHz). The conclusions from the model tests were confirmed by measurements carried out on power transformers.

\section{Investigated Types of Partial Discharges and Electrode Systems Used in Experiment}

Basing on the literature [57-59], surface and interturn discharges were selected for the research, in relation to their high energy and strongly destructive character for power transformer insulation system. Additionally, PDs in oil were investigated, which usually are the initial form of the surface and interturn discharges.

\subsection{Surface Discharges}

Various terms for surface discharges, such as sliding discharge, creeping discharge, or surface tracking discharge, can be found in the literature [60,61]. Surface discharge is the most dangerous type of PD that can lead to a catastrophic failure of a power transformer under normal operating conditions [62]. This phenomenon occurs in the oil/pressboard barrier system, which is the weakest and most problematic area in the power transformer insulation system, because of the accumulation of water molecules (due to moisture migration), contaminations (iron or copper particles, corrosive sulfur) and other aging products (gaseous and solid hydrocarbons). Generally, all insulation systems of the transformer can be treated as systems of the oil barrier type in which the initiation and development of PDs always take place in oil [59]. In an ideal setup of this type, the electric field is perpendicular to the barrier surface and parallel 
(tangential) to the spacing elements (strips and spacers). In this configuration, the ratio of electric field strength in the barrier to electric field strength in the oil channels is inversely proportional to the ratio of the relative permittivity of the barrier $(\varepsilon=3.6-4.7)$ and oil $(\varepsilon=2.2)$. Thus, the electric field strength in the barriers does not exceed $60-70 \%$ of the electric field strength in the oil channels. A breakdown of barriers that are located perpendicularly to the force lines of the electric field can only be a result of discharges in oil. Spacers in oil ducts in the ideal oil barrier system are 'unbreakable' because the cross-stress here is almost the same as stress in the oil channels. The cross-strength of the spacing elements is always greater than their surface dielectric strength. Therefore, the development of PD on strips or spacers can be caused almost exclusively by a loss of surface dielectric strength [63]. The electrical stress on the oil/pressboard interface contains both tangential and normal components of the electric field. However, the formation of surface discharge over the pressboard barrier is more assisted by the tangential component and, according to Sokolov, progresses in four stages [64]:

Stage 1. The discharge begins in the oil, on the edge of the outer winding coil (small area with very strong electric field), and then develops in the form of plasma channel (leader), which is more or less consistent with the direction of electric field force lines. As a result, it comes to the breakdown of an oil duct, between the outer winding coil, and the nearest pressboard barrier.

Stage 2. Upon reaching the barrier, the plasma channel spreads on the barrier surface in the form of creeping sparks, which create-due to high temperature-permanent carbonized, partially conductive paths, so-called 'black marks'. At the initial stage of surface discharge development, there are also 'white marks' observed that indicate a drying out process of the pressboard through moisture evaporation $[60,65,66]$.

Stage 3. Electric field forces that accompany the surface discharges are capable of pulling water and oil out of the cellulose pores, which results in microscopic sparking within the pressboard. High moisture content and an inhomogeneous distribution in the pressboard barrier cause a dangerous current concentration on a narrow path. Then carbonized traces are generated even at very low currents, $\sim 0.1$ $\mathrm{mA}$. Along with the development of this phenomenon, the electric conductivity of the path grows-until breakdown. The electric field forces can accumulate water molecules into the shortest path between the 'electrodes', facilitating the initiation of the high-energy, long creeping sparks [62].

Stage 4 . High-energy sparking not only causes the formation of carbonized traces on the pressboard surface, but also leads-due to dissociation of oil molecules- to the formation of hydrogen [67], gaseous hydrocarbons (mainly $\mathrm{C}_{2} \mathrm{H}_{2}$ and $\mathrm{CH}_{4}$ ), and wax-like substances [68]. As the path length increases, the apparent charge of the surface discharges decreases to $\sim 500 \mathrm{pC}-5 \mathrm{nC}$, and it is high enough to continue the degradation of cellulose. The permanent destruction of cellulose fibers occurs under the influence of PD with an apparent charge of $\sim 1 \mathrm{nC}$. The development of surface discharge can continue from minutes to even years, until the treeing conductive path cause shunting of an essential part in the transformer insulation resulting in a powerful arc [69]. The possible scenarios of surface discharge formation in transformer insulation system are illustrated in Figure 1.

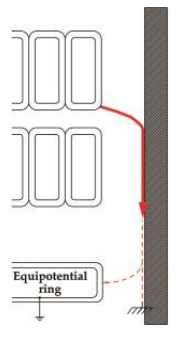

(a)

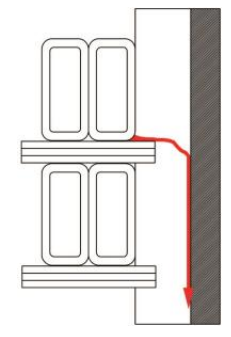

(b)

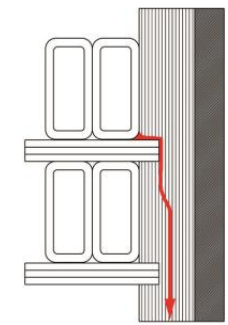

(c)

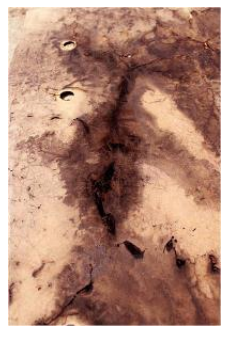

(d)

Figure 1. Possible scenarios of surface discharge formation in transformer insulation system: (a) flashover along the barrier to the earthed construction part or equipotential ring (the flashover bypasses the intercoil spacers); (b) flashover across the surface of intercoil spacer; the discharge may 
later develop along the lateral surface of the strip (or on the surface of barrier-as shown in Figure 1a; (c) breakdown of distance strip; and (d) photo of a fragment $(\sim 450 \times 800 \mathrm{~mm})$ of the pressboard barrier strongly degraded by surface discharges (numerous carbonized traces are visible).

The main three causes of surface discharge initiation are as follows [59].

1. The occurrence of sources of intense ionization, such as

- air bubbles that can get into the transformer tank during the oil filling process [56],

- free water molecules that have settled out of the insulation and oil into a separate layer,

- emulsified water, which is supersaturated in solution but has not yet totally separated from the oil,

- the violent release of water vapor bubbles from cellulose to oil ("bubble effect") [70],

- local electrical overstress in the oil wedge (at the oil-pressboard-electrode triple junction),

- gas bubbles formed by the cavitation in transformer oil. The cavitation phenomenon (defined as the formation of discontinuity areas in a fluid) can be triggered by high temperature (hot spots), oil pumps or core/windings vibrations [71],

- metal particle contamination [31] (see Figure 2).

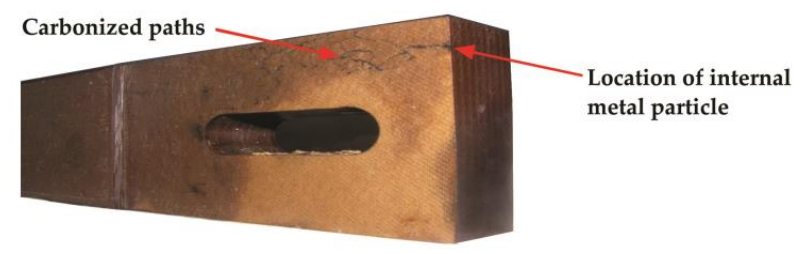

Figure 2. The location of an embedded metal particle under the surface of pressboard beam (the PD tracking originated from this area).

2. The abnormal configuration of the insulation system, that stimulate the generation of surface discharges, such as

- $\quad$ contact or too small distance between pressboard barrier and winding - this situation is usually caused by winding radial deformations (bucklings);

- $\quad$ touch of pressboard barrier to bushing connection terminal; and

- too small of a distance between the supporting beam and transformer tank wall or windings (see Figure 3) [29].

3. The occurrence of local electrical stresses large enough to initiate creeping discharges (tangential electrical component stress $\geq 1 \mathrm{kV} / \mathrm{mm}$ ) [59].

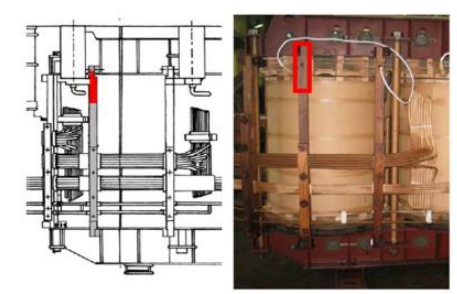

(a)

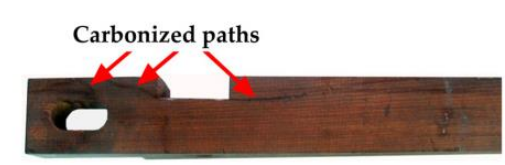

(b)

Figure 3. Example of surface discharge occurrence in a 16 MVA power transformer caused by too small of a distance between the supporting beam and the winding: (a) construction scheme and the picture of transformer active part with marked location of the defect and (b) picture of supporting beam with visible permanent carbonized paths. 
As mentioned before, a necessary condition for the appearance of surface discharges is a presence of the tangential component of the electric field (perpendicular to the dielectric surface). Insulation systems, in which tangential components are primary phenomena (i.e., forced by electrode system), are divided into two groups: (1) insulation systems, which normal components are negligibly small and (2) insulation systems, in which they play an important role.

The first group is typical for all spacing elements, e.g., pressboard strips spacing oil channels or pressboard spacers spacing coils. For generating surface discharges of this type, the presented in Figure 4 electrode system was used (hereinafter referred to as "electrode system A"). A typical representative of the second group (so-called Toepler systems) is an insulation system of bushing insulator or insulation between two windings of different heights (in this case at the end of a lower winding, there occur both tangential and normal components) [60,72-74]. This type of surface discharges was generated in the electrode system (hereinafter referred to as "electrode system B"), which was presented in Figure 5.

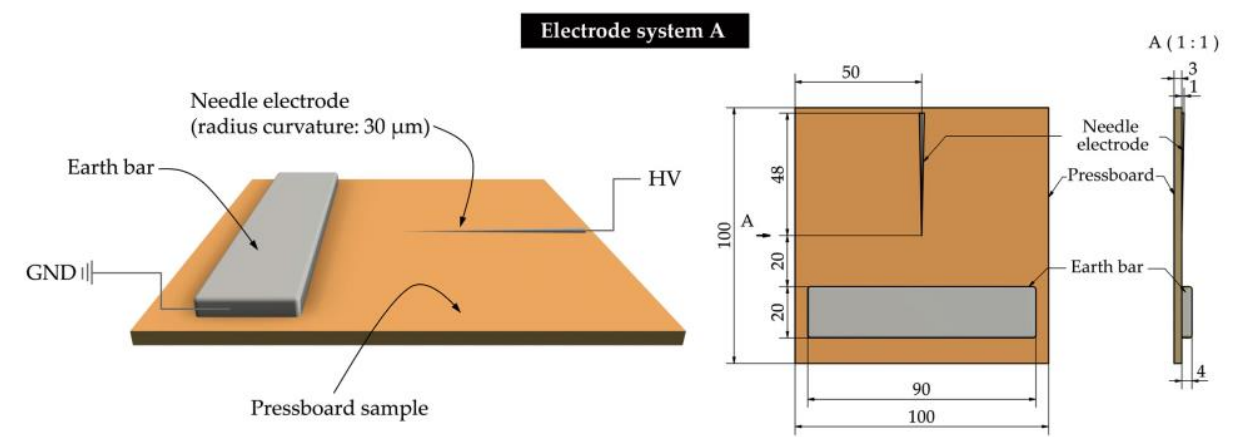

Figure 4. The applied electrode system for generation of surface discharges on pressboard sample in oil with a negligibly small normal component of electric field-electrode system A.

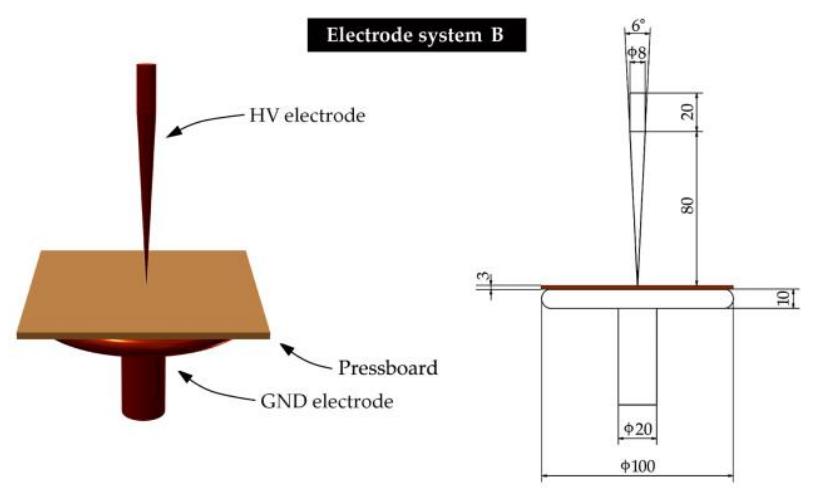

Figure 5. The applied electrode system for generation of surface discharges on a pressboard sample in oil with significant normal component of electric field-electrode system B.

\subsection{Interturn Partial Discharges}

Another very dangerous type of PD for power transformer insulation system is interturn (intercoil) discharge. The following gives the reasons for the occurrence of these discharges.

1. High electrical stress in wedge-shaped oil gaps [75] (see Figure 6a),

2. axial deformation of windings (axial collapse by excessive axial compression, conductors tilting, axial bending of conductors and excessive deflection, winding insulation damage, and/or rupture) $[58,59]$ (see Figure 6b),

3. excessive moisture content leading to a concentration of gas bubbles in oil gaps and ducts [70], and

4. paper and pressboard surface contamination with conductive particles and oil aging products [61]. 
It is estimated that interturn discharges, compared to surface discharges, in a significantly shorter time, may lead to power transformer catastrophic failure. During the defect development, the energy of discharges grows quickly from relatively low level approximately 500-1000 pC to over 100 nC, which causes insulation breakdown and turn-to-turn flashover.

The examples of the destructive influence of interturn discharges on power transformer insulation system were shown in Figure 7, whereas the electrode system, in which this type of discharges was generated, is shown in Figure 8.

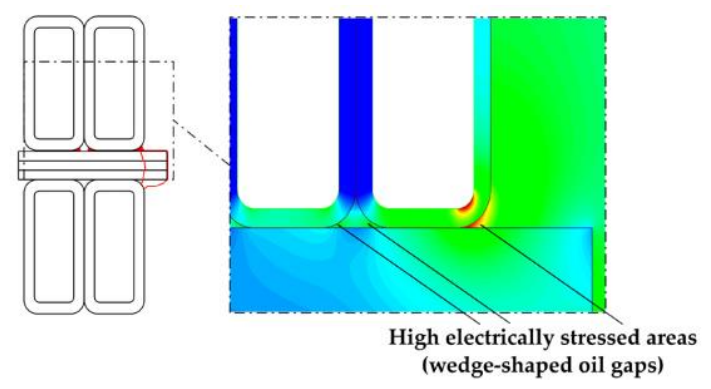

(a)

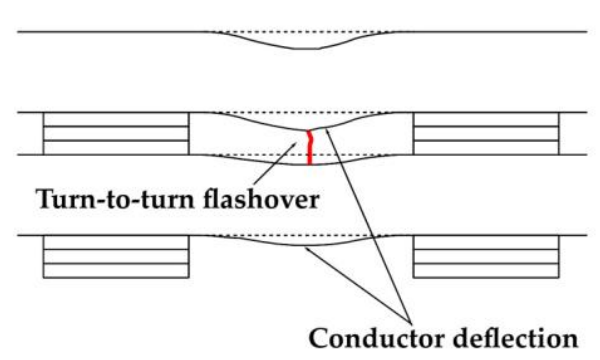

(b)

Figure 6. Possible reasons for interturn discharges in power transformer: (a) high electrically stress areas in wedge-shaped oil gaps and (b) too small insulation spacing caused by excessive axial deflection of conductors (coils).

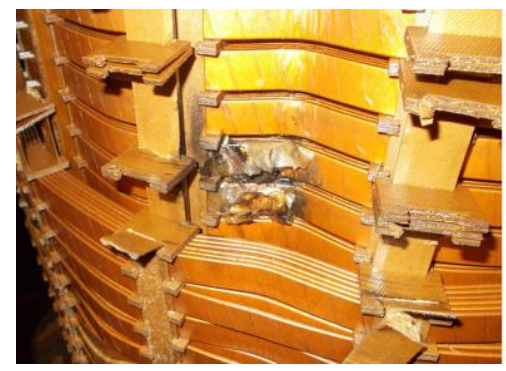

(a)

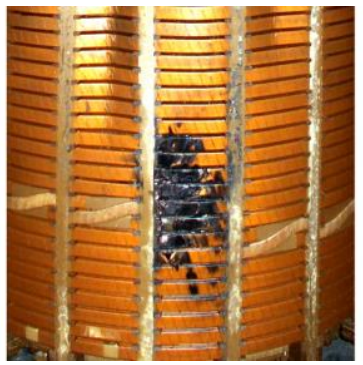

(b)

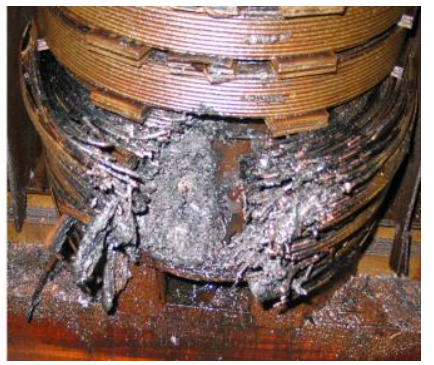

(c)

Figure 7. Pictures presenting consequences of destructive action of interturn discharges: (a) breakdown of paper insulation in the place of the deformed winding, (b) a vast area of carbonized winding insulation, (c) complete destruction of windings and insulation.
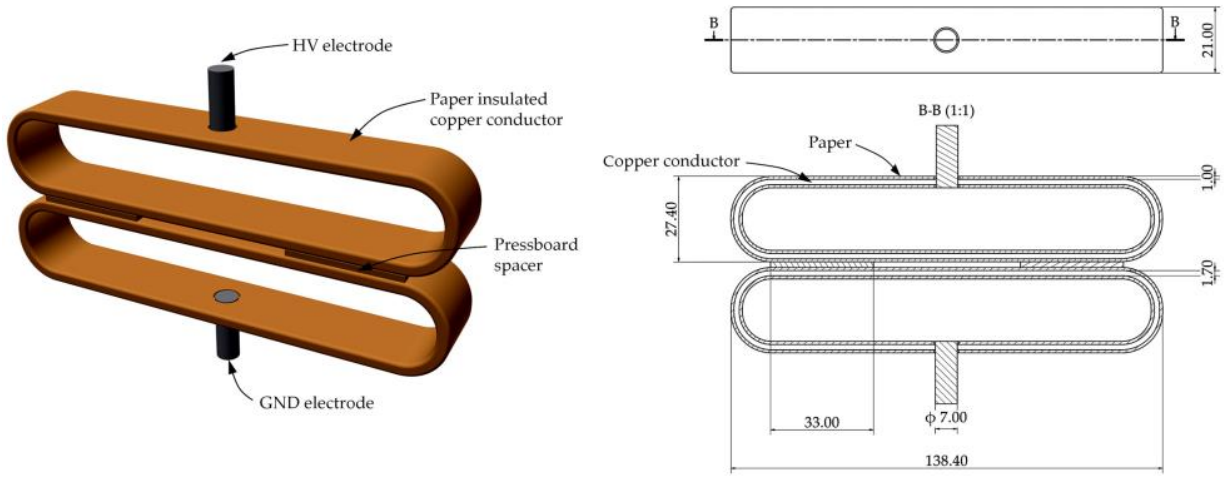

Figure 8. The applied electrode system for generation of interturn discharges. 


\subsection{Partial Discharges in Oil}

For generating PD in oil, the needle-plate electrode system, shown in Figure 9, was applied. Of course, such an electrode system is unacceptable in the main insulation system of the power transformer. However, its properties give a view on the consequences of constructive or technological oversights, e.g., when needle electrode (screw or sharp edge) is a grounded constructive element. Additionally, one may assume that every kind of discharge in a transformer insulation system is always-in its initial stage of development-a discharge in oil, as plasma has no contact with electrodes. The interturn insulation may be an example in which most cases of breakdown occur at the edges of the coil and the discharge is initiated in the oil gap (see Figure 1a).
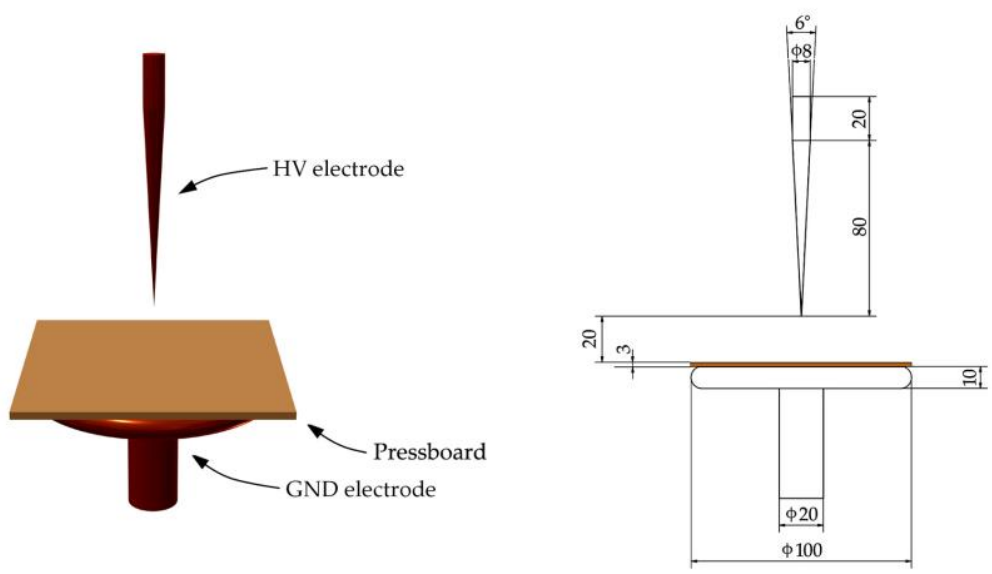

Figure 9. The applied electrode system for the generation of PD in oil.

\section{Measurement Setup}

For investigating the frequency of acoustic signals emitted by partial discharges, broadband (10-1000 kHz) ultrasonic transducer type Olympus V101-RB of relatively flat frequency response curve (without resonance peaks) was used. For comparison, acquisition of AE pulses emitted by PDs was additionally conducted using three piezoelectric sensors, which are commonly applied in power transformer diagnostics, i.e., resonant standard frequency AE sensor type PAC R15D, low-frequency AE sensor type PAC D9241A, and wideband multiresonant AE sensor type PAC WD. The parameters of the transducers applied in the investigation are presented in Table 1.

Table 1. Parameters of the AE sensors used to determine the frequency of acoustic signals emitted by PD in oil-paper insulation.

\begin{tabular}{|c|c|c|c|c|}
\hline \multirow{2}{*}{ Parameter } & \multicolumn{4}{|c|}{ Sensor Type } \\
\hline & Olympus V101-RB & PAC WD & PAC R15D & PAC D9241A \\
\hline Operating frequency range, $\mathrm{kHz}$ & $10-1000$ & $100-1000$ & $50-400$ & $10-100$ \\
\hline 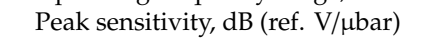 & N/A & -64.25 & -59.70 & -69.2 \\
\hline 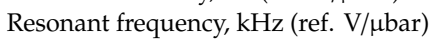 & $550^{1}$ & 522 & 151.37 & 60.31 \\
\hline Output & single-ended & true differential $^{2}$ & differential & differential \\
\hline Category & $\begin{array}{l}\text { Wideband } \\
\text { nonresonant }\end{array}$ & $\begin{array}{l}\text { wideband } \\
\text { multiresonant }\end{array}$ & $\begin{array}{l}\text { standard } \\
\text { resonant }\end{array}$ & low-frequency \\
\hline
\end{tabular}

The electrode systems for generation of the investigated forms of partial discharges described in Section 3 were put in an oil-filled transformer tank of dimensions $1200 \times 800 \times 750 \mathrm{~mm}$. During the measurements, one of the four selected ultrasonic transducers was mounted exactly in front of the defect at distance $\sim 400 \mathrm{~mm}$. As an ultrasonic couplant, silicone grease was used. Acoustic signals emitted by PDs were registered using measurement system type PDtracker Portable I (Poznan University of Technology, Poznan, Poland) [76], equipped with four analog input channels (with simultaneous 
sampling at up to $20 \mathrm{MS} / \mathrm{s}$ ) and preamplifiers with $40 \mathrm{~dB}$ gain and a $20-1000 \mathrm{kHz}$ bandpass filter. Monitoring of partial discharge activity was performed with the use of conventional PD measuring instrument type Doble PD-Smart (Doble Engineering Co, Boston, MA, USA) and test circuit according to IEC 60270 standard (Figure 10) was used. AE signals were registered for such a value of test voltage, at which PD activity was stable (nonextinguishing). The electrical parameters of the investigated types of discharges are presented in Table 2.

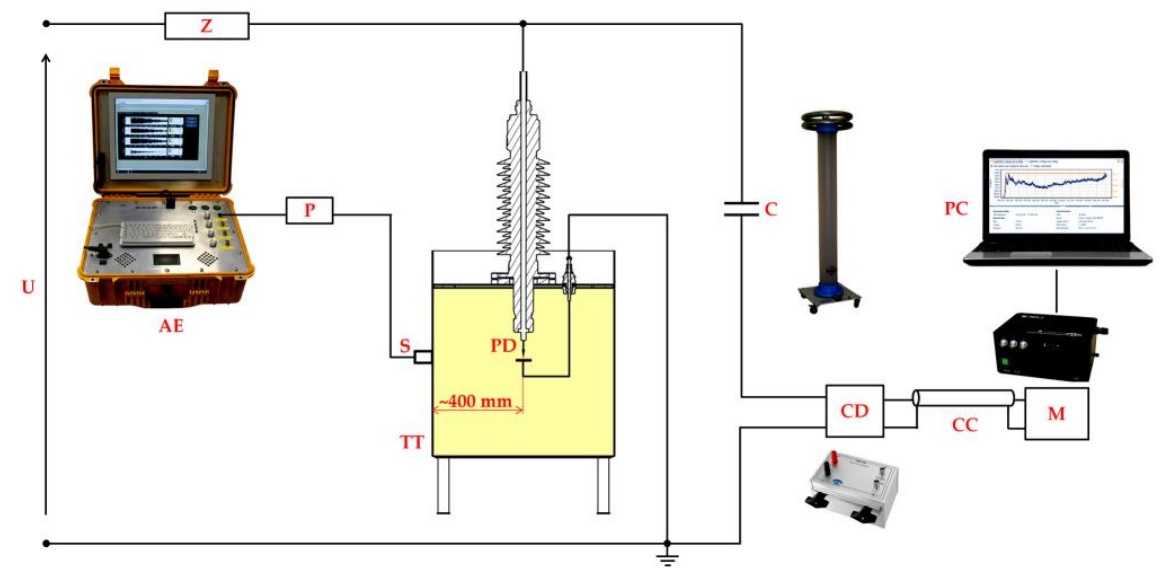

Figure 10. Schematic diagram of the measurement setup: $U=$ high-voltage supply; $Z=$ short-circuit current limiting resistor; $\mathrm{AE}=$ four-channel acoustic emission measuring system; $\mathrm{P}=$ preamplifier; $\mathrm{S}=$ acoustic emission sensor; $\mathrm{TT}=$ oil-filled transformer tank; $\mathrm{PD}=$ electrode system for partial discharge generation; $\mathrm{C}=$ coupling capacitor; $\mathrm{CD}=$ coupling device (measuring impedance); $\mathrm{CC}=$ connecting cable; $\mathrm{M}=$ conventional partial discharge measuring instrument; $\mathrm{PC}=$ computer.

Table 2. The electrical parameters of the investigated types of partial discharges.

\begin{tabular}{|c|c|c|c|c|c|}
\hline \multirow{3}{*}{ PD Type } & \multicolumn{5}{|c|}{ Parameter } \\
\hline & \multirow{2}{*}{$\begin{array}{l}\text { PD Inception Voltage } \\
U_{\mathrm{i}}(\mathrm{kV})\end{array}$} & \multirow{2}{*}{$\begin{array}{l}\text { PD Testing Voltage } \\
\mathrm{U}_{\mathrm{t}}(\mathrm{kV})^{1}\end{array}$} & \multicolumn{3}{|c|}{ Apparent Charge q (pC) } \\
\hline & & & Mean Value $q_{\text {avg }}$ & Maximum Value $q_{\max }$ & Standard Deviation std(q) \\
\hline $\begin{array}{l}\text { Surface discharge } \\
\text { (electrode system A) }\end{array}$ & 19.6 & 20.3 & 410 & 597 & 112 \\
\hline $\begin{array}{l}\text { Surface discharge } \\
\text { (electrode system B) }\end{array}$ & 12.9 & 14.1 & 1115 & 5430 & 155 \\
\hline Interturn discharge & 18.5 & 19.9 & 792 & 3814 & 173 \\
\hline Partial discharge in oil & 21.1 & 21.8 & 126 & 495 & 62 \\
\hline
\end{tabular}

${ }^{1}$ values of test voltage, at which the PD activity was stable (nonextinguishing) and AE pulses were registered.

\section{Results and Discussions}

For each of the investigated PD forms, $500 \mathrm{AE}$ waveforms were registered. Then, for all collected pulses, the average power spectrum density (PSD) was determined based on the peak hold averaging technique. Peak hold averaging is performed at each frequency line separately, retaining peak levels from one FFT record to the next. Because peak hold averaging retains the peak levels of the averaged quantities, it is possible to detect all harmonic components that transfer most of the signal energy [77,78].

The elaborated averaged PSD were shown together with the frequency response curves of the used AE sensors in Figures 11-14. 


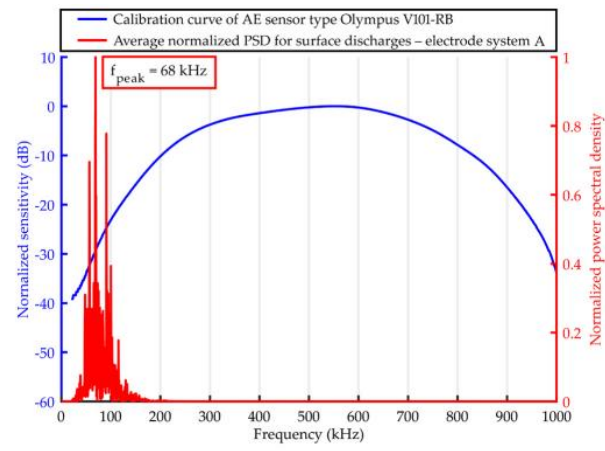

(a)

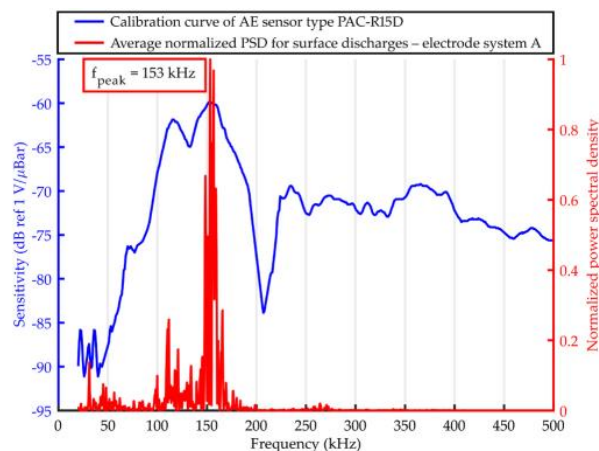

(c)

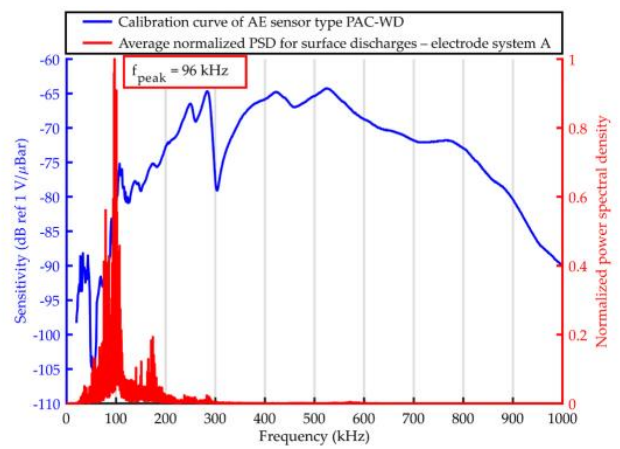

(b)

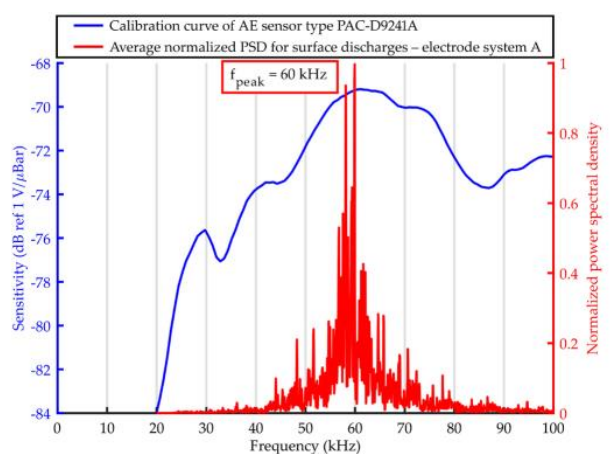

(d)

Figure 11. Average normalized power spectrum density (PSD) determined for acoustic emission (AE) signals emitted by surface discharges (generated in electrode system A) and registered with the use of ultrasonic sensor type: (a) Olympus V101-RB, (b) PAC WD, (c) PAC R15D, and (d) PAC D9241A.

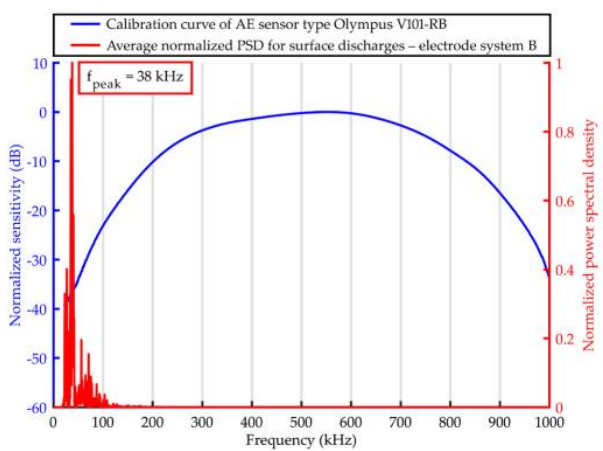

(a)

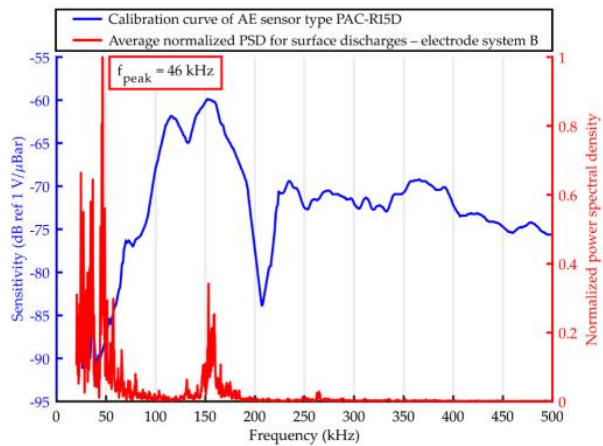

(c)

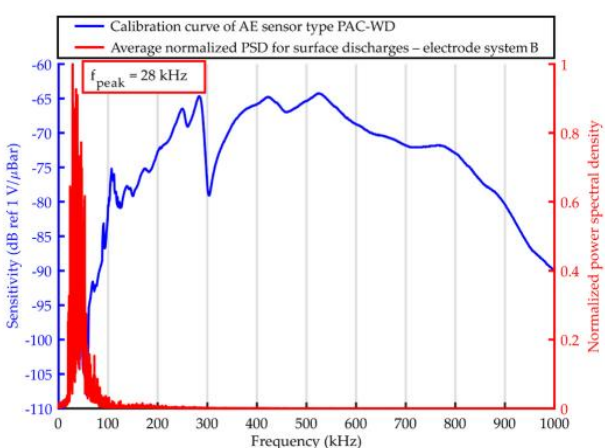

(b)

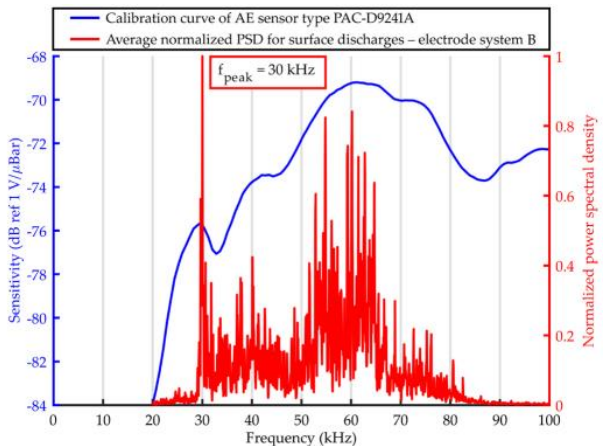

(d)

Figure 12. Average normalized PSD determined for AE signals emitted by surface discharges (generated in the electrode system B) and registered with the use of ultrasonic sensor type: (a) Olympus V101-RB, (b) PAC WD, (c) PAC R15D, and (d) PAC D9241A. 


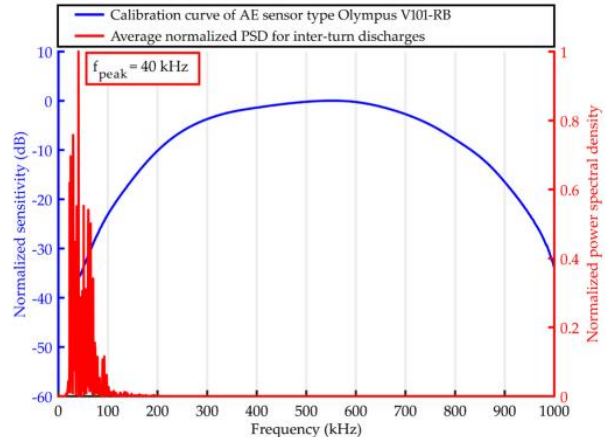

(a)

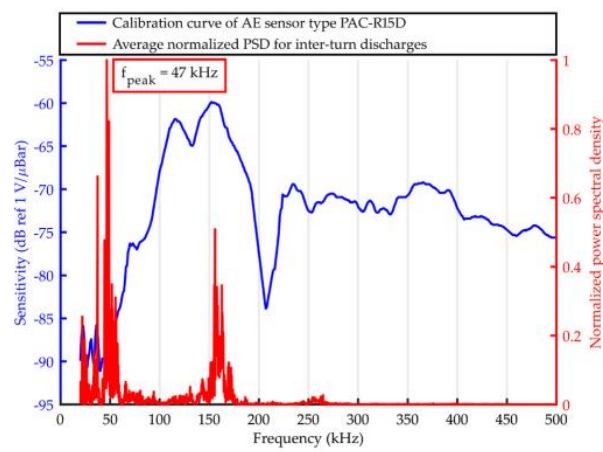

(c)

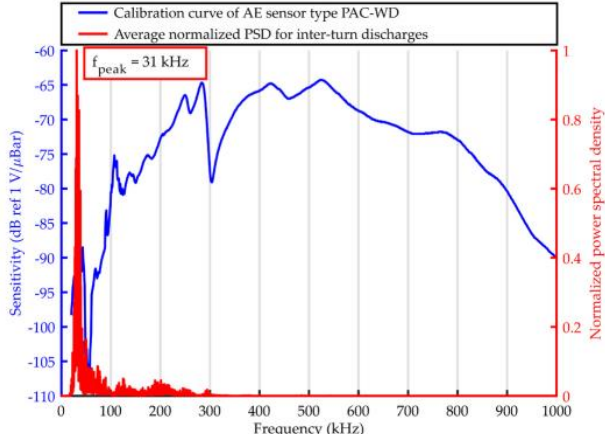

(b)

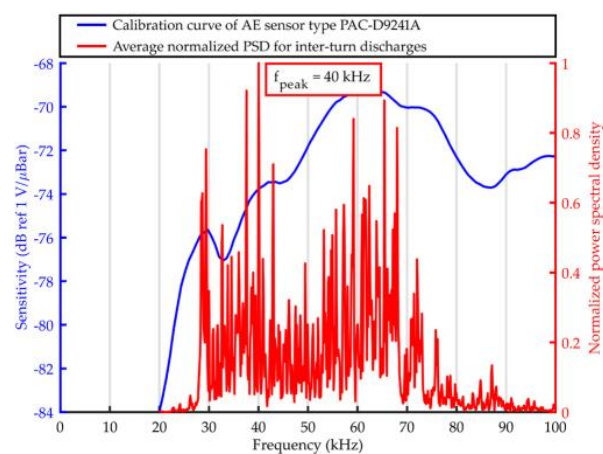

(d)

Figure 13. Average normalized PSD determined for AE signals emitted by interturn discharges and registered with the use of ultrasonic sensor type: (a) Olympus V101-RB, (b) PAC WD, (c) PAC R15D, and (d) PAC D9241A.

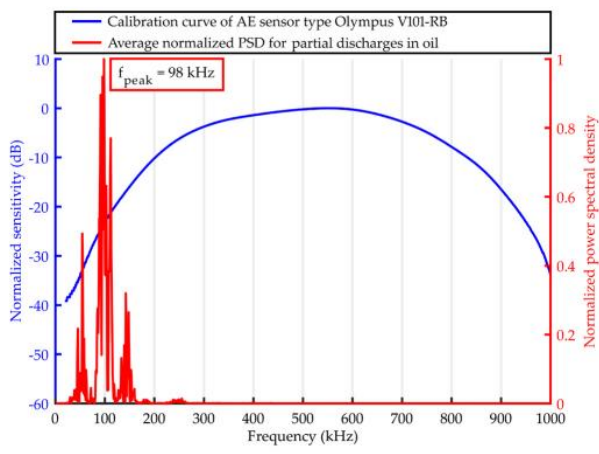

(a)

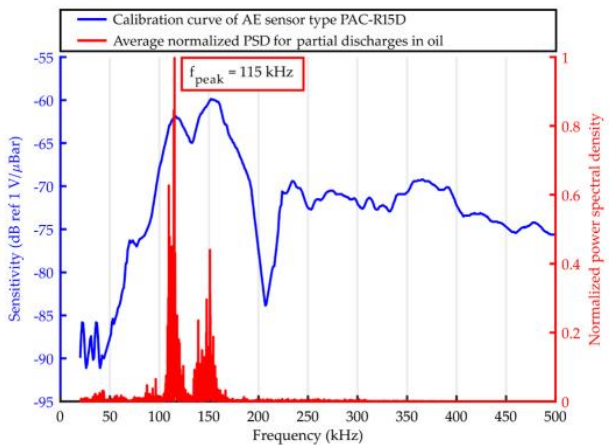

(c)

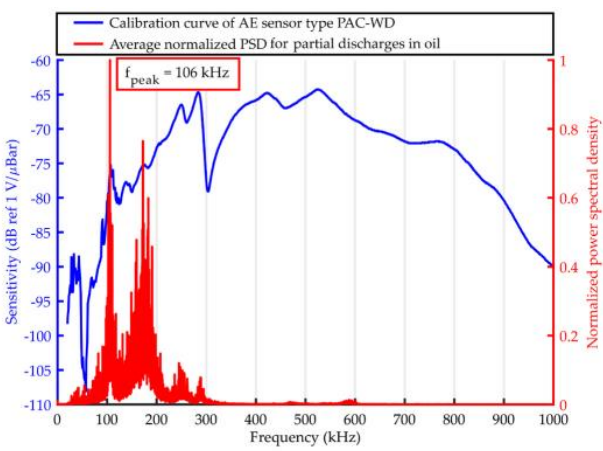

(b)

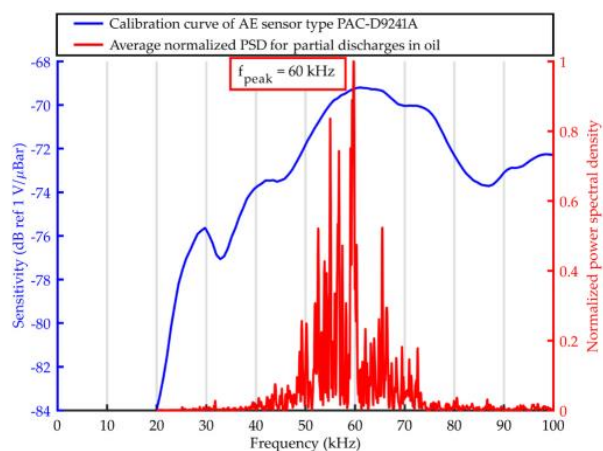

(d)

Figure 14. Average normalized PSD determined for AE signals emitted by partial discharges in oil and registered with the use of ultrasonic sensor type: (a) Olympus V101-RB, (b) PAC WD, (c) PAC R15D, and (d) PAC D9241A. 
For the elaborated average PSD, besides peak frequency $f_{\text {peak }}$ (point in the spectrum at which the peak magnitude is observed), frequency centroid $f_{\text {centroid }}$ and weighted peak frequency $\left\langle f_{\text {peak }}\right\rangle$ were determined as well (Table 3). Frequency centroid is an average weighted frequency that takes into account the whole spectrum (it indicates the location of the "center of mass" of the PSD). Thus the frequency centroid gives a fuller picture of the AE signal's frequency content than the peak frequency. The parameter is described with the formula below.

$$
f_{\text {centroid }}=\frac{\sum_{k=1}^{N} k \cdot F[k]}{\sum_{k=1}^{N} F[k]},
$$

where $F[k]$ is the magnitude corresponding to bin $k$ in the frequency spectrum.

In turn, weighted peak frequency $\left\langle f_{\text {peak }}\right\rangle$ is a geometric mean of frequency peak $f_{\text {peak }}$ and frequency centroid $f_{\text {centroid }}$ :

$$
\left\langle f_{\text {peak }}\right\rangle=\sqrt{f_{\text {peak }} \cdot f_{\text {centroid }}}
$$

Table 3. Frequency-domain parameters determined on the basis of the average PSD of AE pulses

\begin{tabular}{|c|c|c|c|c|}
\hline \multirow[b]{2}{*}{ PD Type } & \multirow[b]{2}{*}{ AE Sensor } & \multicolumn{3}{|c|}{ Frequency Domain Parameter } \\
\hline & & $\begin{array}{l}\text { Peak Frequency } \\
(\mathbf{k H z})\end{array}$ & $\begin{array}{c}\text { Frequency Centroid } \\
(\mathbf{k H z})\end{array}$ & $\begin{array}{c}\text { Weighted Peak Frequency } \\
(\mathbf{k H z})\end{array}$ \\
\hline \multirow{4}{*}{$\begin{array}{l}\text { Surface discharge } \\
\text { (electrode system A) }\end{array}$} & Olympus V101-RB & 68.3 & 78.6 & 73.3 \\
\hline & PAC WD & 96.3 & 117.2 & 106.2 \\
\hline & PAC R15D & 153.3 & 142.3 & 147.7 \\
\hline & PAC D9241A & 60.1 & 60.9 & 60.5 \\
\hline \multirow{4}{*}{$\begin{array}{l}\text { Surface discharge } \\
\text { (electrode system B) }\end{array}$} & Olympus V101-RB & 37.6 & 44.5 & 40.9 \\
\hline & PAC WD & 28.4 & 48.2 & 37.0 \\
\hline & PAC R15D & 46.4 & 83.2 & 62.1 \\
\hline & PAC D9241A & 30.0 & 53.8 & 40.2 \\
\hline \multirow{4}{*}{ Interturn discharge } & Olympus V101-RB & 40.3 & 48.9 & 44.4 \\
\hline & PAC WD & 30.9 & 72.3 & 47.3 \\
\hline & PAC R15D & 46.6 & 100.2 & 68.4 \\
\hline & PAC D9241A & 40.0 & 53.5 & 46.3 \\
\hline \multirow{4}{*}{$\begin{array}{l}\text { Partial discharge } \\
\text { in oil }\end{array}$} & Olympus V101-RB & 98.1 & 100.9 & 99.5 \\
\hline & PAC WD & 105.8 & 167.7 & 133.2 \\
\hline & PAC R15D & 115.2 & 127.5 & 121.2 \\
\hline & PAC D9241A & 59.7 & 59.0 & 59.3 \\
\hline
\end{tabular}
emitted by the investigated forms of partial discharges.

Based on the results obtained with the use of Olympus V101-RB, the following conclusions may be drawn.

- From all the investigated PD forms, AE signals of the lowest frequency were emitted by the surface discharges generated in the electrode system $B$, in which the normal component of the electric field plays a significant role. The frequency of the AE signals ranged between $20 \mathrm{kHz}$ and $110 \mathrm{kHz}$, wherein $95 \%$ of the energy was transferred in a narrow band from $22 \mathrm{kHz}$ to $42 \mathrm{kHz}$. In turn, surface discharges generated in electrode system A, in which normal component is negligibly small, emitted AE signals of higher frequencies. This kind of surface discharge transferred $95 \%$ of the acoustic wave energy in the band between $48 \mathrm{kHz}$ and $100 \mathrm{kHz}$. Frequency centroid was $78.6 \mathrm{kHz}$ and a peak frequency $68.3 \mathrm{kHz}$ (for surface discharges generated in electrode system $\mathrm{B}$, it was $44.5 \mathrm{kHz}$ and $37.6 \mathrm{kHz}$, respectively). 
- The values of frequency parameters of interturn discharges were slightly higher (by about $2-5 \mathrm{kHz}$ ) than parameters of surface discharges generated in electrode system $B$. The dominating frequency band, in which $95 \%$ of the AE pulses energy was transferred, was in the range of 20 to $68 \mathrm{kHz}$.

- AE signals of the higher frequency generated discharges in oil, which, opposite to the remaining PD forms, had broadband character. In PSD, one may distinguish three separate frequency bands, i.e., $43-64 \mathrm{kHz}, 80-117 \mathrm{kHz}$, and $131-155 \mathrm{kHz}$. However, the largest part of the energy $(90.3 \%)$ was transferred in the band of $80-117 \mathrm{kHz}$, and the peak frequency was equal to $98.1 \mathrm{kHz}$.

Considering the results obtained with the use of the remaining transducers, one may formulate the following additional conclusions.

- Independently of the kind of the used transducers for surface discharges with significant normal components of the electric field (electrode system B) and for interturn discharges, AE signals of low frequency $(<50 \mathrm{kHz})$ were registered.

- Resonant and multiresonant transducers do not enable to precisely detect frequencies of AE signal emitted by PD (they coincide with main or side-band resonance frequency).

- In the case of both broadband transducers (Olympus 101-RB, PAC WD), a clear relation between the investigated form of the partial discharge and frequency centroid of emitted AE signals was observed. In Figure 15, one may see that the more energetic the given type of the discharges was, the more "center of mass" of the spectrum (frequency centroid) moved to the lower frequencies.

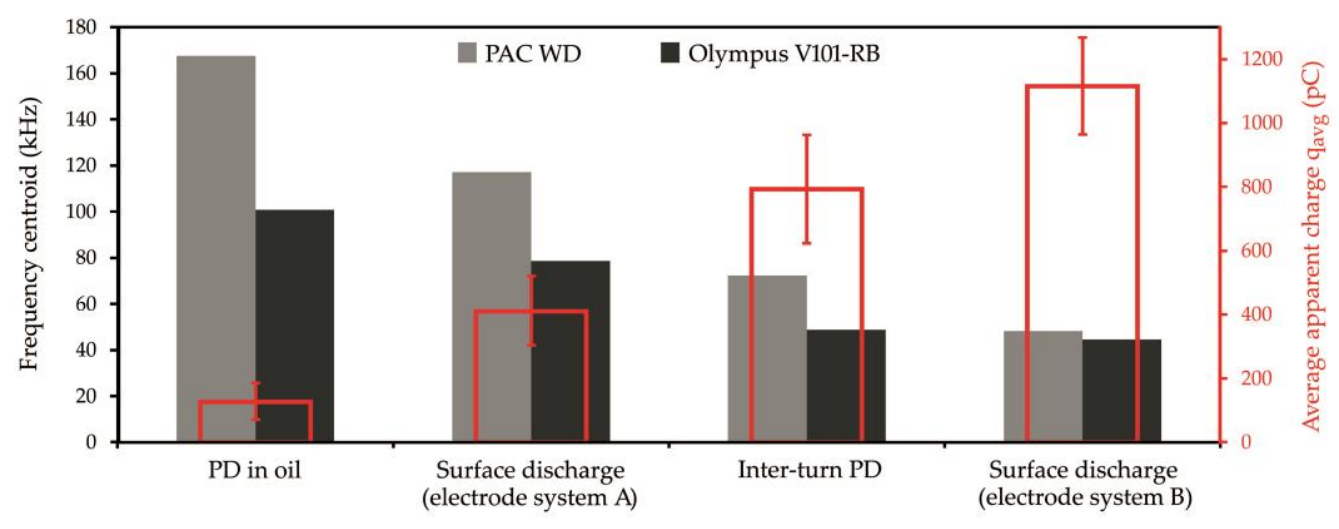

Figure 15. Influence of type and energy (value of apparent charge) of partial discharge on the centroid frequency of registered AE signal.

In order to obtain a more complex picture of the frequencies of the AE signals emitted by the PDs, all power density spectra collected using a broadband sensor type V101-RB (Figure 16) were summed and normalized. The analysis of the resultant spectrum allows to distinguish three main frequency bands, in which the most energy of acoustic waves originating from surface discharge, interturn discharge, and discharge in oil was transferred, i.e., $20-45 \mathrm{kHz}, 50-70 \mathrm{kHz}$, and 85-115 kHz. Furthermore, in these bands, one may distinguish the dominating frequencies, which equal to $40 \mathrm{kHz}$, $68 \mathrm{kHz}$, and $90 \mathrm{kHz}$, respectively. Basing on this, one may formulate a thesis that the optimal AE sensor for PD detection in power transformers should be a multiresonant transducer, in which the calibration response curve has peaks at the frequencies mentioned above. One should not forget the possible sources of disturbances occurring in power transformer. Luckily, the majority of them, like pumps and fans, emit acoustic signals of frequency below $30 \mathrm{kHz}$. However, in extreme cases, the frequency of noise associated with the deformation of magnetic domains in the transformer core may even reach $50 \mathrm{kHz}$ [41]. Nevertheless, usually acoustic signals generated by the Barkhausen effect have too low energy to excite the transducer. Additionally, they are effectively attenuated by the paper insulated windings and thick pressboard barriers. Therefore, one may assume that the ideal compromise linking 
high sensitivity of the PD detection and resistance to external disturbances is an ultrasonic transducer with a bandwidth of 30 to $115 \mathrm{kHz}$ and resonances at $68 \mathrm{kHz}$ and $90 \mathrm{kHz}$. In Section 6, each stage of designing and manufacturing of the transducer, which meets the above requirements, is presented.

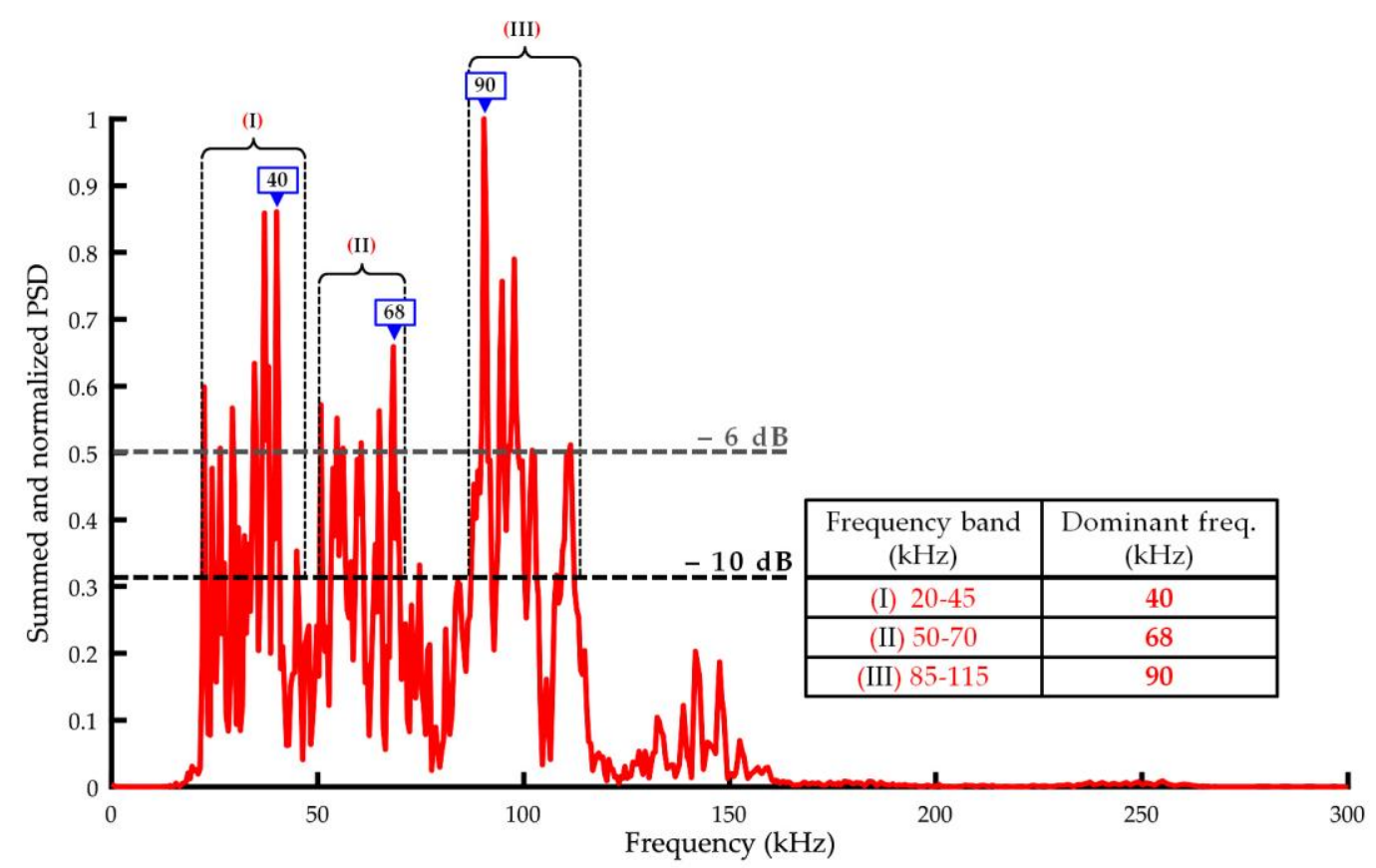

Figure 16. Summed and normalized PSD obtained for all investigated types of PD.

\section{Design and Fabrication of Prototype AE Sensor}

For prediction of transducer resonant frequencies, the Krimholtz-Leedom-Matthaei (KLM) [79] model is currently most often used. Compared to other ultrasonic transducer models, like RLC [80], Mason [81] and Redwood model [82], its main advantage is the separation of the acoustical and electrical parts of the transduction process (Figure 17).

Due to that, it is possible to analyze these parts individually to improve the design of all transducer components, i.e., matching layer, piezoelectric element, backing layer, and electrical matching network. Moreover, the KLM model helps to design and optimize the transducers of a more complex, multilayer structure [83,84]. A detailed description of the KLM model may be found in the source publication [79], as well as many other papers in which authors present the design process of piezoelectric transducers' based on this method [85-87].

The input parameters consist of the thickness of the piezoelectric material $d$, the area of the electrodes $A$, and the acoustic impedances of the main transducer elements: the piezoelectric crystal $Z_{0}$, backing layer $Z_{B}$, and matching layer $Z_{M}$. Moreover, the model comprises the input capacitance $C_{0}$ and input electrical reactance $X_{1}$. The acoustical side of the KLM model is fixed to the electrical side by a transformer with a turns ratio $(1: \varphi)$. This transformer converts the electrical signal into the proper acoustic values. 


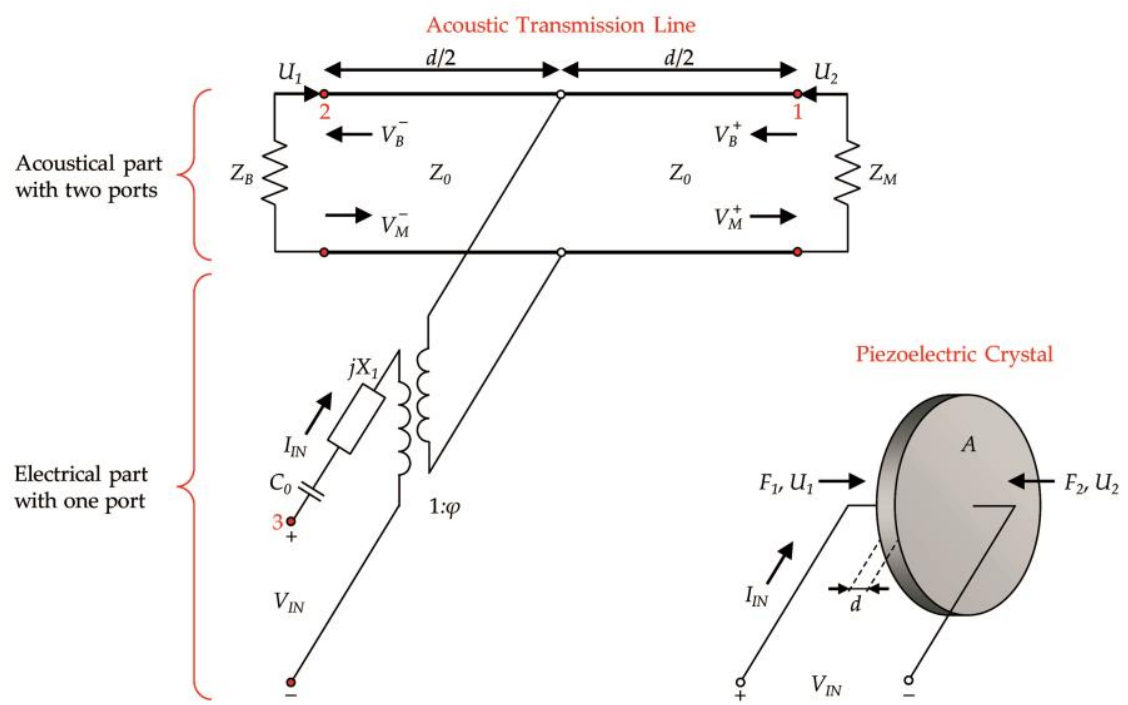

Figure 17. Schematic diagram of the Krimholtz-Leedom-Matthaei (KLM) model of a piezoelectric transducer.

The equations for input parameters of the KLM model are given below [34].

$$
\begin{gathered}
Z_{0}=\rho c A=A \sqrt{\rho c_{33}^{D}} \\
C_{0}=\frac{\varepsilon_{33}^{S} A}{d} \\
X_{1}=\frac{h_{33}^{2} A}{\omega^{2} Z_{0}} \sin \left(\frac{\omega d}{c}\right) \\
\varphi=\frac{\omega Z_{0}}{2 h_{33} \sin (\omega d / 2 c)} \\
h_{33}=k_{t} \sqrt{c_{33}^{D} / \varepsilon_{33}^{S}}
\end{gathered}
$$

where $\rho$ is the density of the piezoceramic material $\left(\mathrm{kg} / \mathrm{m}^{3}\right), c$ is the velocity of longitudinal acoustic waves $(\mathrm{m} / \mathrm{s}), c_{33}^{D}$ is the elastic stiffened for constant electric displacement $\left(\mathrm{N} / \mathrm{m}^{2}\right), \varepsilon_{33}^{S}$ is the clamped (high-frequency) dielectric constant, $\varphi$ is the electromechanical transformer ratio of the KLM model, $h_{33}$ is the piezoelectric constant $(\mathrm{V} / \mathrm{m})$, and $k_{t}$ is the electromechanical coupling factor.

Based on the value of the acoustic impedance (in Rayl or Pa.s $/ \mathrm{m}^{3}$ ) of piezoelectric crystal $Z_{0}$, the matching layer $Z_{M}$, backing layer $Z_{B}$, and the input impedances for both layers may be determined as follows

$$
\begin{aligned}
Z_{I N, M} & =Z_{0} \frac{Z_{M}+j Z_{0} \tan (\omega d / 2 c)}{Z_{0}+j Z_{M} \tan (\omega d / 2 c)} \\
Z_{I N, B} & =Z_{0} \frac{Z_{B}+j Z_{0} \tan (\omega d / 2 c)}{Z_{0}+j Z_{B} \tan (\omega d / 2 c)}
\end{aligned}
$$

Considering the transmission line theory, the value of the input impedance $Z_{I N}$ of the electrical port can be calculated based on Equation (10):

$$
Z_{I N}=\frac{1}{j \omega C_{0}}+j X_{1}+\frac{Z_{a}}{\varphi^{2}}
$$

where $Z_{a}$ is the impedance as seen looking into the acoustic transmission line: 


$$
Z_{a}=\frac{Z_{I N, M} Z_{I N, B}}{Z_{I N, M}+Z_{I N, B}}
$$

$Z_{I N}$ relates to the real impedance measured by the impedance analyzer. The minimum impedance frequency on the $Z_{I N}(f)$ plot is the resonant frequency, at which the piezoceramic element vibrates most readily and most efficiently transforms the mechanical energy into electrical energy. In turn, the maximum impedance frequency is also the anti-resonance frequency.

In order to ensure efficient transmission of acoustic waves energy from mineral oil through steel power transformer tank to the transducer's piezoelectric components, it is necessary to apply matching layer, which optimal impedance value should be the geometric mean of the impedances of steel $\left(Z_{s}\right)$ and the piezoelectric material $\left(Z_{P Z T}\right)$ :

$$
Z_{M}=\sqrt{Z_{S} Z_{P Z T}}
$$

Assuming the acoustic impedance of the steel equals $Z_{S}=46.2 \mathrm{MRayl}$ and selected piezoelectric ceramics $Z_{P Z T}=31.5 \mathrm{MRayl}$ (see Table 5), then the optimal value of matching layer acoustic impedance should total 38.15 MRayl. Therefore, high-density alumina $\left(\mathrm{Al}_{2} \mathrm{O}_{3}\right)$, with an impedance that equals approx. 36-37 MRayl, is usually the first choice material for the design and manufacture of matching layer for $\mathrm{AE}$ sensors, that are supposed to be mounted at all kinds of metal structures (transformers, reactors, storage tanks, pipelines, bridges, etc.). In the case of the designed sensor, the disc with the diameter of $25 \mathrm{~mm}$ and height of $1 \mathrm{~mm}$ manufactured from high-purity alumina and acoustic impedance equal to 37.9 MRayl is the matching layer. Basic parameters of the ceramics are summarized in Table 4 .

Table 4. Properties of the high-purity alumina used for matching layer.

\begin{tabular}{lcc}
\hline \multicolumn{1}{c}{ Properties } & Value & Unit \\
\hline Main component & $\alpha-\mathrm{Al}_{2} \mathrm{O}_{3}$ & - \\
Purity & $>99.5$ & $\mathrm{wt}-\%$ \\
Density & 3950 & $\mathrm{~kg} / \mathrm{m}^{3}$ \\
Open porosity & 0 & $\mathrm{vol.} \%$ \\
Average size of crystallites & 10 & $\mu \mathrm{m}$ \\
Compressive strength & 3500 & $\mathrm{MPa}$ \\
Young's modulus & 380 & $\mathrm{GPa}$ \\
Poission's ratio & 0.22 & - \\
Hardness & 23 & $\mathrm{GPa}$ \\
Acoustic velocity & 9600 & $\mathrm{~m} / \mathrm{s}$ \\
Acoustic impedance & 37.9 & $\mathrm{MRayl}$ \\
\hline
\end{tabular}

Two sensing elements (piezoceramic discs) with opposite polarization directions and different geometries were used as active components. The technology based on two piezoelectric elements is used by Physical Acoustics Company [39]. This way, for example, a multiresonant sensor type PAC WD is produced, in which the piezoceramic ring and the axially placed disc are the active elements. Such a fully differential design offers a number of advantages, of which the most important are

- multiresonance frequency response curve (it has two main resonance frequency in thickness vibration mode),

- $\quad$ high sensitivity and low noise (because differential preamplifier multiplies the difference between two input signals and simultaneously eliminates common-mode noise), and

- broader bandwidth in comparison to single-ended resonant $\mathrm{AE}$ sensor. 
For manufacturing active elements, piezoelectric ceramics PZT type 5A (Navy Type II) was selected, which has high charge sensitivity and operates over a wide temperature range. Properties of the used piezoelectric material are summarized in Table 5.

Table 5. Properties of the piezoelectric ceramic used.

\begin{tabular}{|c|c|c|c|}
\hline Properties & Symbol & Value & Unit \\
\hline Relative dielectric constant & $K^{T}$ & 1900 & - \\
\hline \multicolumn{4}{|l|}{ Electromechanical coupling coefficients: } \\
\hline Longitudinal coupling coefficient & $k_{33}$ & 0.72 & - \\
\hline Transverse coupling coefficient & $k_{31}$ & 0.36 & - \\
\hline Shear coupling coefficient & $k_{15}$ & 0.68 & - \\
\hline Planar coupling coefficient & $k_{p}$ & 0.63 & - \\
\hline \multicolumn{4}{|l|}{ Piezoelectric charge constants: } \\
\hline $\begin{array}{l}\text { Induced polarization in direction } 3 \text { (parallel to direction in which ceramic } \\
\text { element is polarized) per unit stress applied in direction } 3\end{array}$ & $d_{33}$ & $400 \times 10^{-12}$ & $\mathrm{C} / \mathrm{N}$ \\
\hline $\begin{array}{l}\text { Induced polarization in direction } 3 \text { per unit stress applied in direction } 1 \\
\text { (perpendicular to the direction in which ceramic element is polarized) }\end{array}$ & $d_{31}$ & $175 \times 10^{-12}$ & $\mathrm{C} / \mathrm{N}$ \\
\hline $\begin{array}{l}\text { Induced polarization in direction } 1 \text { per unit shear stress applied about a } \\
\text { direction perpendicular to the direction in which ceramic element is } \\
\text { polarized }\end{array}$ & $d_{15}$ & $590 \times 10^{-12}$ & $\mathrm{C} / \mathrm{N}$ \\
\hline Dielectric dissipation factor (dielectric loss) ${ }^{1}$ & $\tan \sigma$ & $\leq 2.00$ & $\%$ \\
\hline \multicolumn{4}{|l|}{ Frequency constants: } \\
\hline Frequency constant for thickness vibration mode & $N_{T}$ & 2040 & $\mathrm{~Hz} \cdot \mathrm{m}$ \\
\hline Frequency constant for planar vibration mode & $N_{P}$ & 1980 & $\mathrm{~Hz} \cdot \mathrm{m}$ \\
\hline Frequency constant for longitudinal vibration mode & $N_{L}$ & 1500 & $\mathrm{~Hz} \cdot \mathrm{m}$ \\
\hline Curie Point ${ }^{2}$ & $T_{C}$ & 360 & ${ }^{\circ} \mathrm{C}$ \\
\hline Density & $\rho$ & 7600 & $\mathrm{~kg} / \mathrm{m}^{3}$ \\
\hline Acoustic impedance & Z & 31.5 & MRayl \\
\hline
\end{tabular}

${ }^{1}$ At $1 \mathrm{kHz}$, low field; ${ }^{2}$ Maximum operating temperature $=$ Curie point $/ 2{ }^{3}$ or $\mathrm{m} / \mathrm{V}$.

Calculations based on the KLM model showed that the resonance frequencies of thickness vibration mode will be equal to $68 \mathrm{kHz}$ and $90 \mathrm{kHz}$ if piezoelectric discs of height $25 \mathrm{~mm}$ and $18.8 \mathrm{~mm}$, respectively, are applied. The presented in Figure 18 results of simulation in form of input impedance characteristics $Z_{I N}(f)$ also allowed to recognize anti-resonance frequencies (at maximum impedance), which for selected PZT discs totaled $80.8 \mathrm{kHz}$ and $107.1 \mathrm{kHz}$.

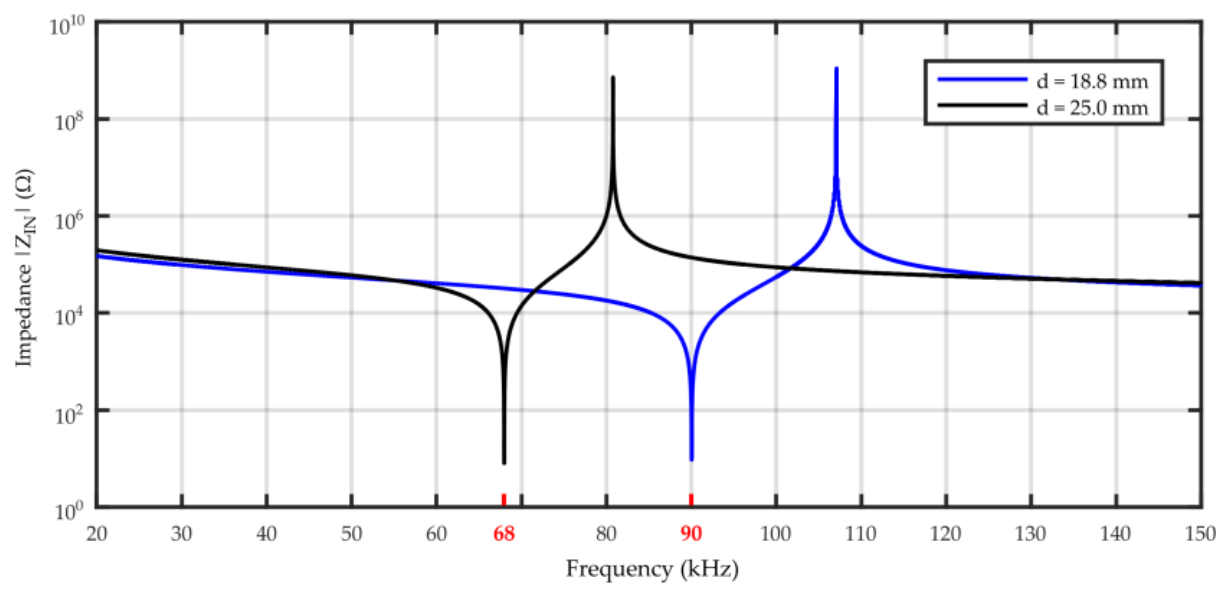

Figure 18. Simulated input impedance $Z_{I N}(f)$ measurement based on the KLM model for piezoelectric discs with a height of $18.8 \mathrm{~mm}$ and $25 \mathrm{~mm}$. 
Thickness vibration mode is the main operating mode of AE sensor because partial discharges in oil generate only longitudinal acoustic waves. However, the transducer is mounted outside the power transformer tank. In practice, it means that besides longitudinal waves, it also registers shear waves (structure-borne waves), which propagate in power transformer tank wall. This proves that resonance frequencies of radial vibration mode should also be equal to $68 \mathrm{kHz}$ and $90 \mathrm{kHz}$. A transducer with such properties would surely guarantee excellent sensitivity of PD detection. Unfortunately, the main limitation in its realization is the necessity of use of piezoelectric discs with very large diameters. In order to obtain the resonance frequency of radial vibration mode, the disc diameter should be equal to $22 \mathrm{~mm}$, and even $\sim 29 \mathrm{~mm}$ for $68 \mathrm{kHz}$. Such a transducer would have large dimensions and weight. Therefore, in the selection of $10.15 \mathrm{~mm}$ diameter of piezoelectric elements, mainly the matters of optimal use of matching layer surface and minimal weight of the transducer were taken into account. Piezoelectric elements were mounted to the matching layer using silver-epoxy electrically conductive adhesive and equipped in signal leads. Schematic diagram, technical drawing with the dimensions and picture of the prototype transducer were presented in Figure 19. The transducer was given a name A6890, which refers to its two main resonant frequencies: $68 \mathrm{kHz}$ and $90 \mathrm{kHz}$.
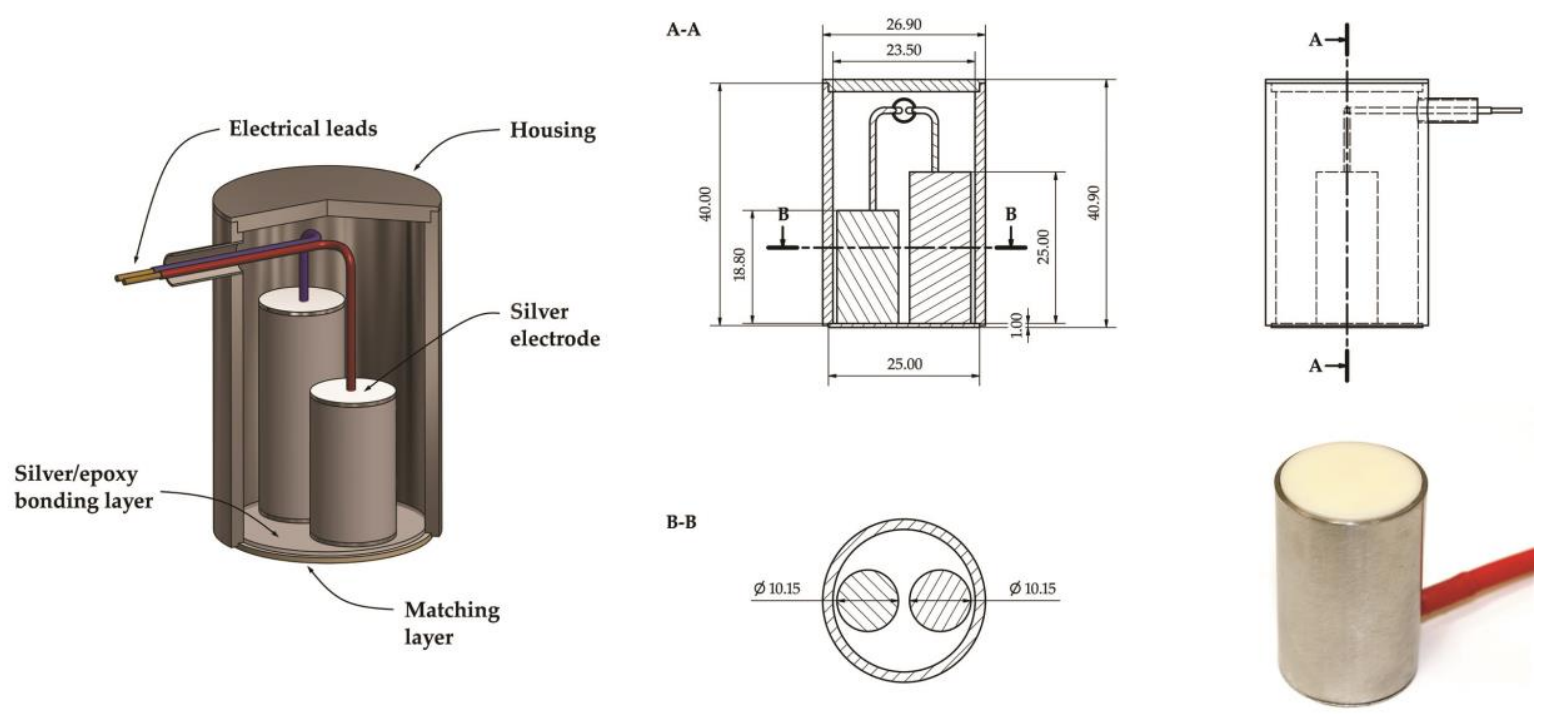

Figure 19. Schematic diagram, technical drawing with dimensions and photo of prototype AE sensor named A6890.

The calibration of the prototype transducer was carried out according to ASTM E976-10: Standard Guide for Determining the Reproducibility of Acoustic Emission Sensor Response [88]. Analysis of the presented in Figure 20 frequency response curve shows that main resonant frequencies $(68.7 \mathrm{kHz}$ and $89 \mathrm{kHz}$ ) of the prototype transducer only slightly differ from the desired values, i.e., $68 \mathrm{kHz}$ and $90 \mathrm{kHz}$. Moreover, the transducer is characterized by high sensitivity (peak sensitivity: $-61.1 \mathrm{~dB}$ ref. $\mathrm{V} / \mu \mathrm{bar})$ and wide bandwidth (30-100 kHz). 


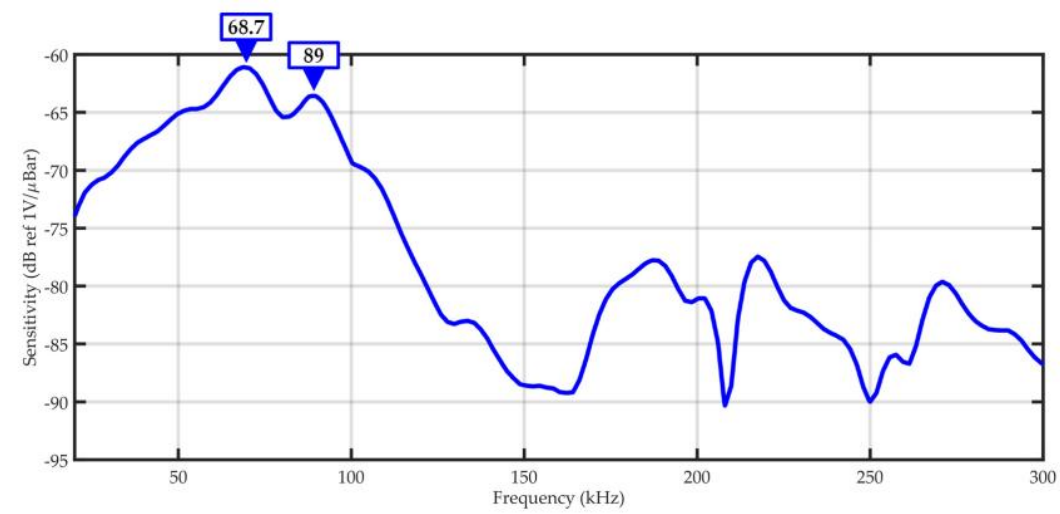

Figure 20. The frequency response curve of the prototype AE sensor type A6890.

Moreover, in frames of the conducted research works, the AE transducer was manufactured in version dedicated to operate in online monitoring system. For that purpose, the AE sensor was integrated with a waterproof housing, in which printed circuit boards of a low-noise preamplifier with $40 \mathrm{~dB}$ gain and active filters were placed. Due to the use of low-noise instrumentation and operational amplifiers (AD8421BRZ, ADA4898, and AD813ARZ), the noise level at the output of this AE signal conditioning unit with $40 \mathrm{~dB}$ gain and with connected ultrasonic transducer did not exceed $1.6 \mathrm{mV} \mathrm{p}_{\mathrm{p}-\mathrm{p}}$. The detailed information concerning these circuits was presented by the author in [34]. The housing was equipped with magnetic holders, which assure constant contact pressure between the transducer front face and transformer tank wall (Figure 21).

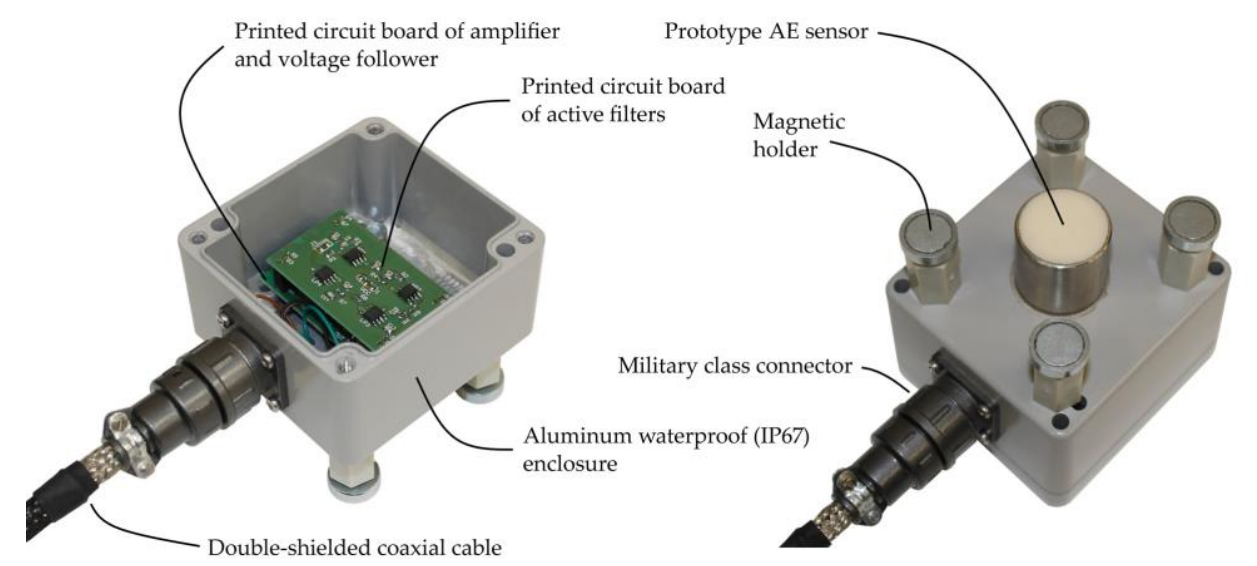

Figure 21. Prototype AE sensor integrated with IP67 waterproof preamplifier housing equipped with magnetic holders.

\section{Sensitivity Tests of Prototype AE Sensor}

In order to assess the efficiency of the prototype AE sensor, laboratory research was carried out, during which surface discharges, interturn discharges, and discharges in oil were generated. AE signals emitted by PDs were registered simultaneously with prototype transducer and three commercial ones, i.e., PAC R15D, PAC D9241A, and PAC WD. The ultrasonic transducers were located on power transformer tank in order to be placed closest to each other and at the same distance from the PD source equal to $\sim 400.5 \mathrm{~mm}$. The schematic diagram of the measurement setup is presented in Figure 22. 


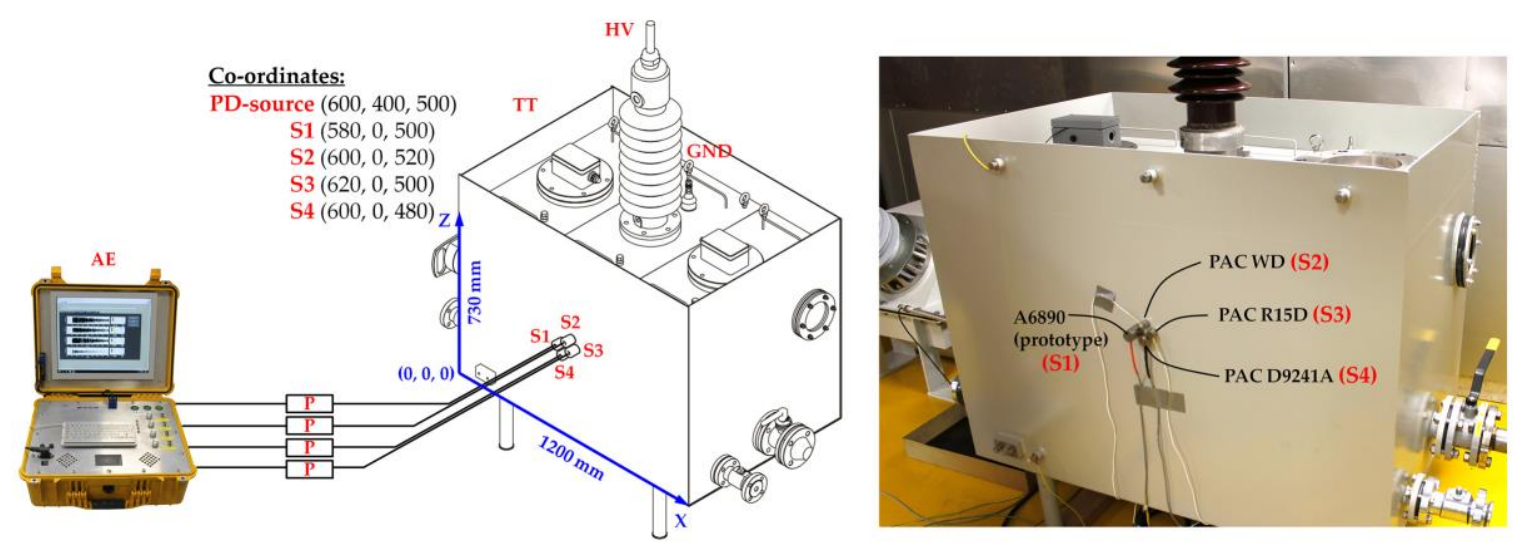

Figure 22. Schematic diagram of measurement setup and photo of the transformer tank installed in electromagnetic shielded laboratory: $\mathrm{AE}$ = four-channel acoustic emission measuring system; $\mathrm{P}=$ preamplifier with $40 \mathrm{~dB}$ gain; S1, S2, S3, and S4 = acoustic emission sensors; $\mathrm{HV}=$ high-voltage bushing; GND = ground; TT = oil-filled transformer tank.

The detection sensitivity of the prototype PD sensor was assessed based on the comparative analysis with earlier mentioned three commercial transducers. In order to achieve this goal, for collected $N=500$ sets of AE waveforms, the average signal amplitude gain was calculated as follows

$$
\overline{a_{v}}=\frac{\sum_{i=1}^{N} 20 \log \left(\frac{A_{p}}{A_{r e f}}\right)}{N}
$$

where $\overline{a_{v}}$-average signal amplitude gain (dB); $A_{p}$ —amplitude of AE signal registered with prototype sensor $(\mathrm{V})$; $A_{\text {ref }}$-amplitude of AE signal registered with one of commercial reference sensor $(\mathrm{V})$; and $N$-the number of AE waveforms sets.

The obtained results of the comparative analysis are presented graphically in Figure 23. In turn, in Figure 24 representative AE waveforms registered for the investigated PD forms are collected.

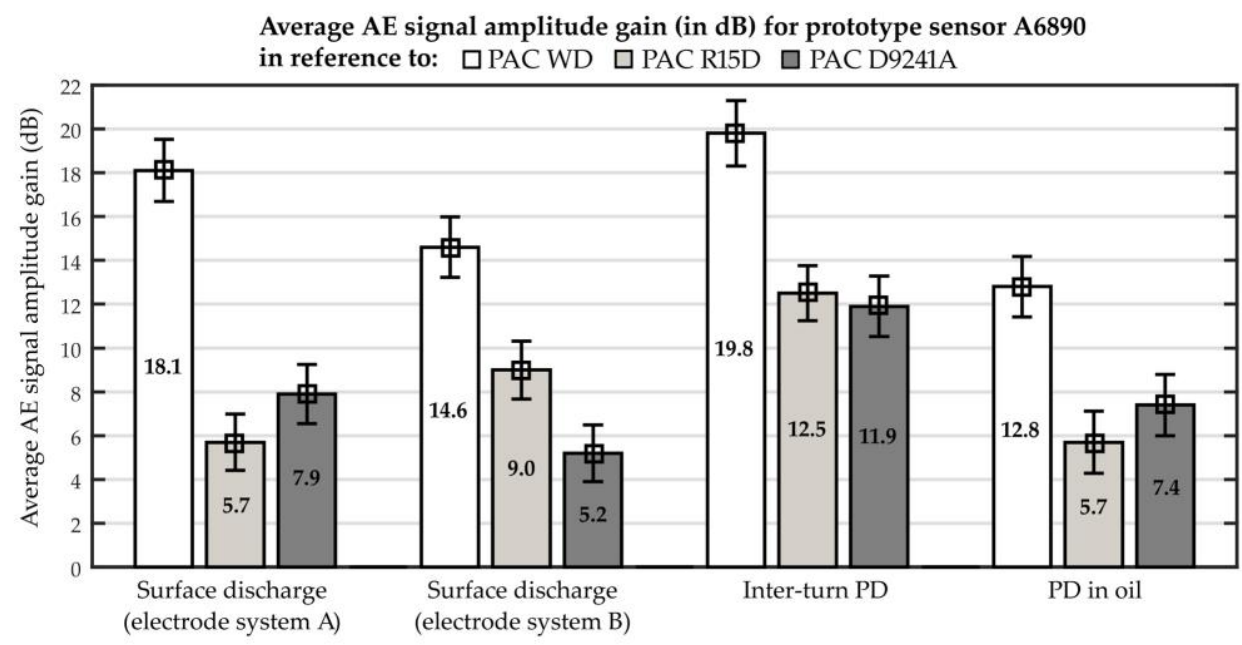

Figure 23. Average AE signal amplitude gain for prototype sensor A6890 in reference to commonly used commercial sensors: PAC WD, PAC R15D, and PAC D9241A. 
Surface PD (electrode system A)

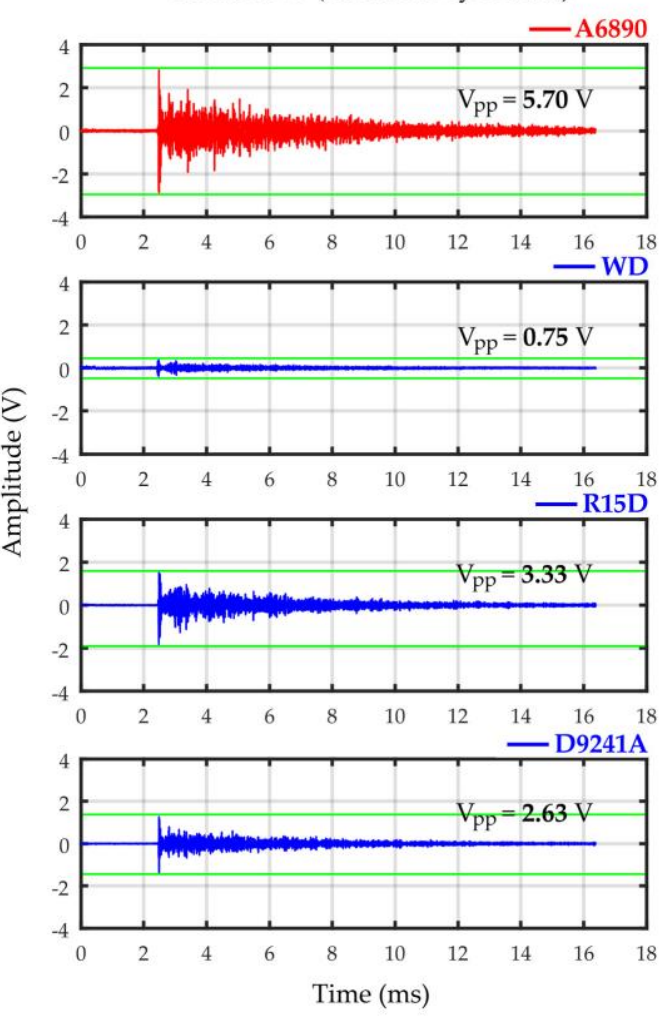

(a)

Inter-turn PD

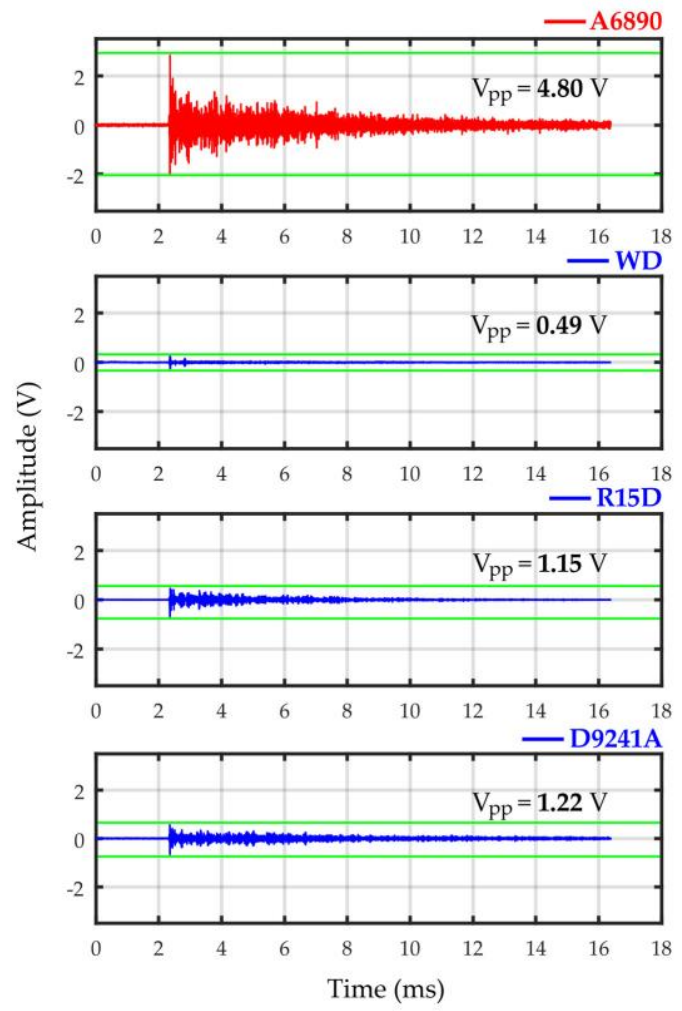

(c)
Surface PD (electrode system B)

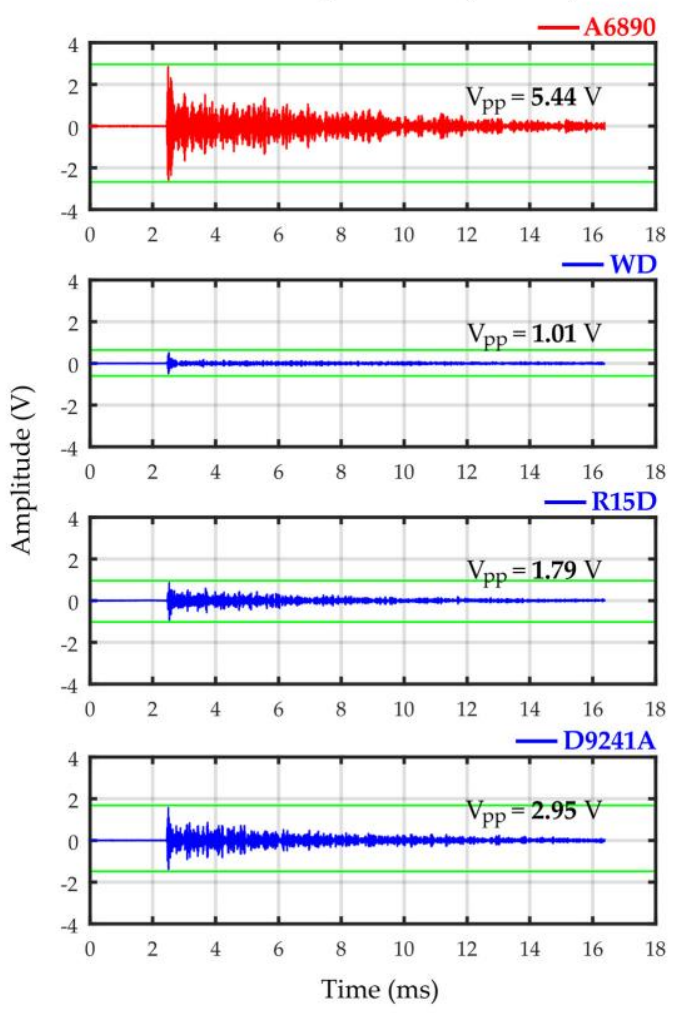

(b)

PD in oil
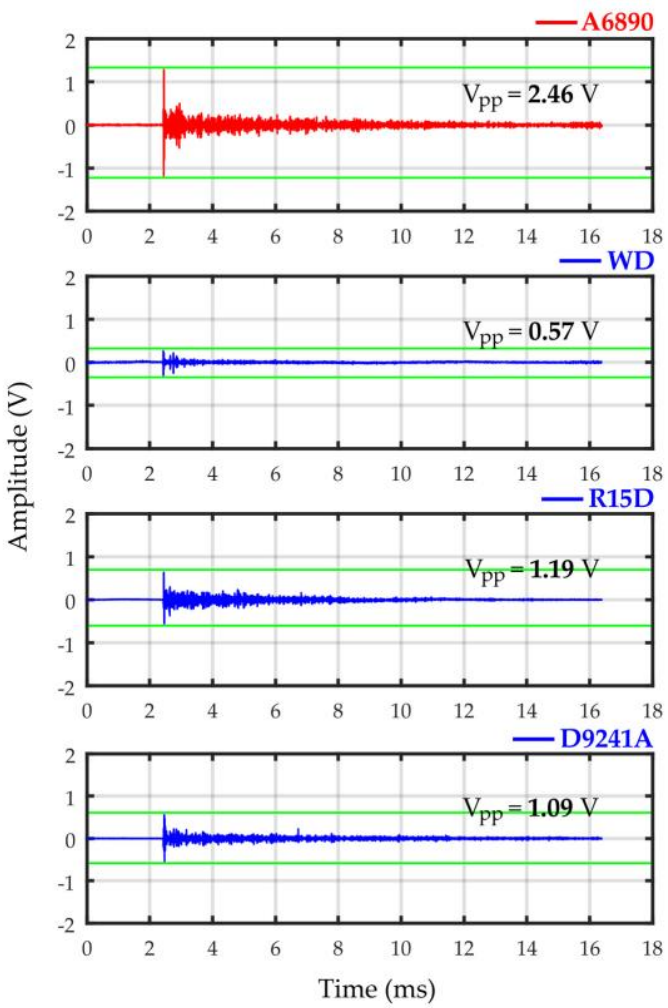

(d)

Figure 24. Comparison of typical AE waveforms registered for (a) surface PD generated in electrode system A, (b) surface PD generated in electrode system B, (c) interturn PD, and (d) PD in oil with the use of prototype (A6890) and commercial AE sensors (PAC WD, PAC R15D, and PAC D9241A). 
The analysis results prove that due to optimization of the transducer frequency response curve and application of two sensing elements, a very high detection sensitivity of partial discharges typical for power transformer insulation system was obtained. The highest differences in favor of prototype sensor were noted for interturn discharges. From the three commercial transducers, the low-frequency sensor type D9241A was characterized by the highest detection sensitivity of interturn discharges. Comparing to that sensor, the amplitude of the AE pulses registered with prototype sensor A6890 was $\sim 3.9$ higher (11.9 dB signal amplitude gain). The lowest difference was observed for surface discharges generated in the electrode system with a significant normal component of the electric field (electrode system B). In this case, the amplitude of the registered AE pulses was, on average, $\sim 1.8$ higher than for sensor D9241A and 2.8 times higher than for sensor R15D, which was respectively $5.2 \mathrm{~dB}$ and $9 \mathrm{~dB}$ signal amplitude gain.

The frequency analysis of the AE pulses registered with prototype sensor A6890 (Figure 25) showed large similarity to the results obtained with broadband sensor type Olympus V101-RB. As expected, the highest similarity was noted for surface discharges generated in electrode system A with negligibly small normal component of the electric field. For both transducers, frequency peak value $f_{\text {peak }}$ in the spectrum was identical $(68 \mathrm{kHz})$. In turn, for surface discharges generated in electrode system $\mathrm{B}$ with significant normal component of the electric field, the difference was equal to only $2 \mathrm{kHz}\left(f_{\text {peak }}=38 \mathrm{kHz}\right.$ for Olympus V101-RB and $f_{\text {peak }}=36 \mathrm{kHz}$ for A6890). In the case of the remaining investigated PD types, the differences were slightly higher and equal $7 \mathrm{kHz}$ for interturn discharges $\left(f_{\text {peak }}=40 \mathrm{kHz}\right.$ for Olympus V101-RB and $f_{\text {peak }}=47 \mathrm{kHz}$ for A6890) and $9 \mathrm{kHz}$ for partial discharges in oil $\left(f_{\text {peak }}=98 \mathrm{kHz}\right.$ for Olympus V101-RB and $f_{\text {peak }}=89 \mathrm{kHz}$ for A6890).

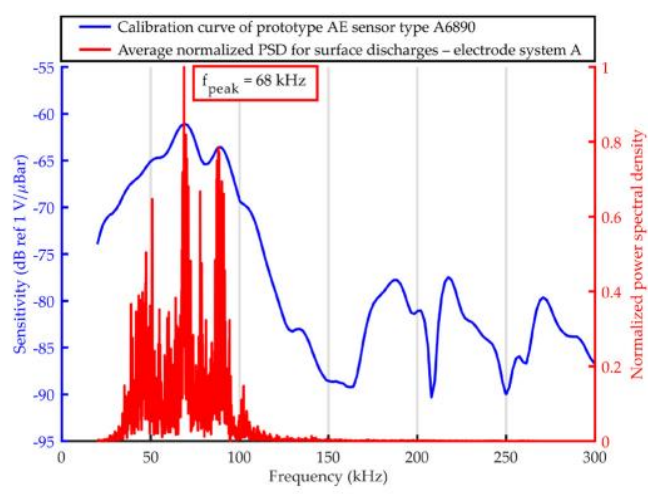

(a)

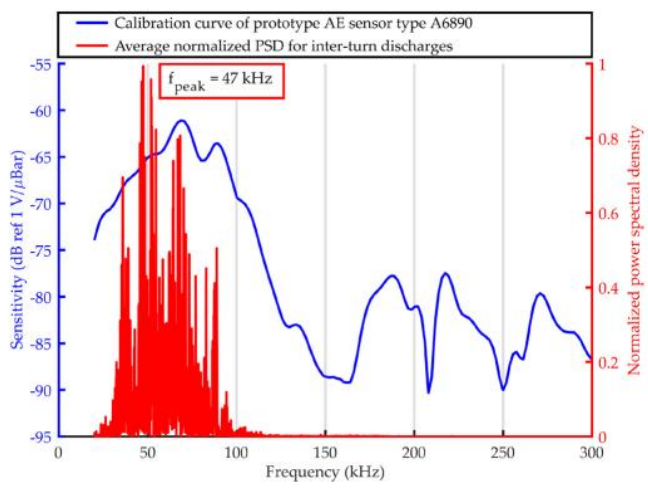

(c)

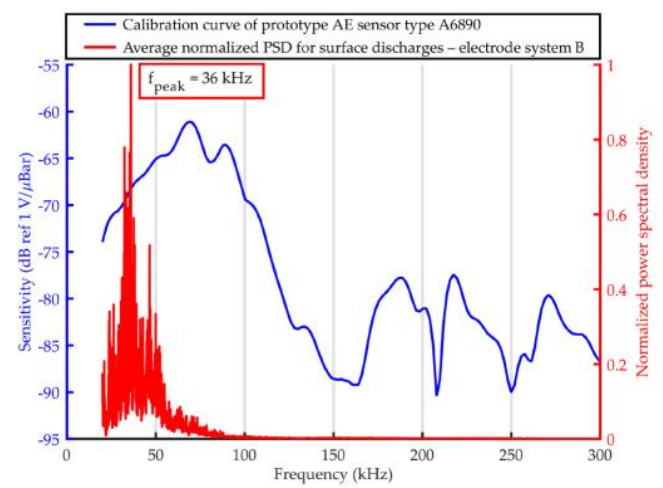

(b)

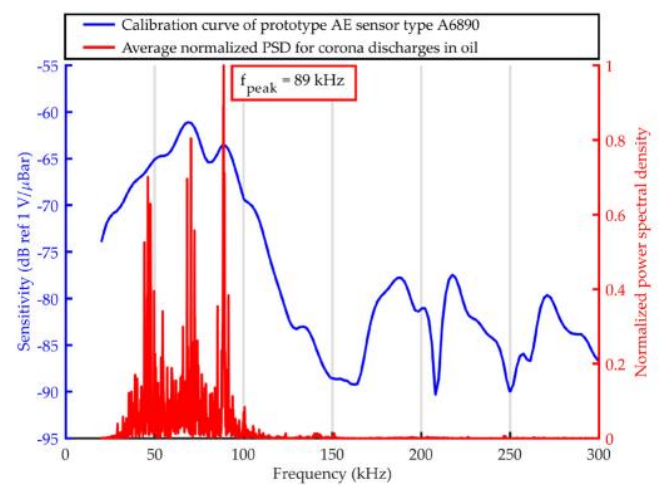

(d)

Figure 25. Average normalized PSD determined for AE signals emitted by (a) surface discharges generated in electrode system A, (b) surface discharges generated in electrode system B, (c) interturn discharges, and (d) partial discharges in oil, registered with the use of prototype AE sensor type A6890. 


\section{Conclusions}

A prototype AE sensor (named A6890) optimized for partial discharge detection in oil-filled power transformers was presented in the article. The main resonant frequencies of the A6890 sensor were selected based on extensive laboratory research, which allowed identification of acoustic frequencies emitted by partial discharges in oil-paper insulation. The measurement results showed that typical for power transformer forms of PDs generate AE signals, in which energy is transmitted in three main ranges: $20-45 \mathrm{kHz}, 50-70 \mathrm{kHz}$, and $85-115 \mathrm{kHz}$, and dominant frequencies are equal to $40 \mathrm{kHz}, 68 \mathrm{kHz}$, and $90 \mathrm{kHz}$, respectively. In the lowest band (20-45 kHz), noise associated with the deformation of magnetic domains in the transformer core and external acoustic disturbances may occur. Therefore, the prototype AE sensor was designed in order to operate in two remaining bands: $50-70 \mathrm{kHz}$ and 85-115 kHz. For its manufacturing, two piezoelectric discs with opposite polarization directions and different heights were used. Fully differential design allowed to obtain the desired properties of the transducer, i.e., (1) two resonant frequencies for longitudinal acoustic waves (peaks at $68.7 \mathrm{kHz}$ and

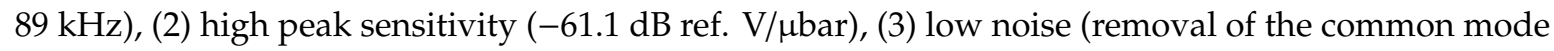
noise by the differential amplifier), and (4) wide frequency response $(\sim 30-100 \mathrm{kHz})$. The laboratory tests confirmed that the prototype transducer is characterized by ultrahigh sensitivity of partial discharge detection. Compared to popular commercial AE sensors, the average amplitude signal gain by a minimum $5.2 \mathrm{~dB}$, and a maximum $19.8 \mathrm{~dB}$ was noted.

Funding: This work was supported by the Polish National Centre for Research and Development, within the Applied Research Programme, grant No. PBS3/A4/12/2015.

Conflicts of Interest: The author declares no conflicts of interest.

\section{References}

1. Tenbohlen, S.; Jagers, J.; Vahidi, F.; Bastos, G.; Desai, B.; Diggin, B.; Fuhr, J.; Gebauer, J.; Krüger, M.; Lapworth, J.; et al. Transformer Reliability Survey; Technical Brochure 642 CIGRE: Paris, France, 2015.

2. Martin, D.; Marks, J.; Saha, T. Survey of Australian power transformer failures and retirements. IEEE Electr. Insul. Mag. 2017, 33, 16-22. [CrossRef]

3. Bossi, A.; Dind, J.E.; Frisson, J.M.; Khoudiakov, U.; Light, H.F.; Narke, D.V.; Verdon, J. An international survey on failures in large power transformers in service. Cigré Electra 1993, 88, 21-48.

4. Dombek, G.; Gielniak, J.; Wroblewski, R. Fire safety and electrical properties of mineral oil/synthetic ester mixtures. In Proceedings of the IEEE 2017 International Symposium on Electrical Insulating Materials (ISEIM), Toyohashi, Japan, 11-15 September 2017; pp. 227-230.

5. Dombek, G.; Gielniak, J. Fire safety and electrical properties of mixtures of synthetic ester/mineral oil and synthetic ester/natural ester. IEEE Trans. Dielectr. Electr. Insul. 2018, 25, 1846-1852. [CrossRef]

6. Christina, A.J.; Salam, M.A.; Rahman, Q.M.; Wen, F.; Ang, S.P.; Voon, W. Causes of transformer failures and diagnostic methods-A review. Renew. Sustain. Energy Rev. 2018, 82, 1442-1456.

7. Chakravorti, S.; Dey, D.; Chatterjee, B. Recent Trends in the Condition Monitoring of Transformers; Springer: London, UK, 2013.

8. Lopatkiewicz, R.; Nadolny, Z. Temperature field on high voltage power transformer. Prz. Elektrotech. 2008, $84,50-52$.

9. Tenbohlen, S.; Coenen, S.; Djamali, M.; Müller, A.; Samimi, M.H.; Siegel, M. Diagnostic Measurements for Power Transformers. Energies 2016, 9, 347. [CrossRef]

10. Nadolny, Z.; Dombek, G.; Przybylek, P.; Przadka, D. Thermal properties of mineral oil admixed with $\mathrm{C}_{60}$ and $\mathrm{TiO}_{2}$ nanoparticles. In Proceedings of the 2016 IEEE Conference on Electrical Insulation and Dielectric Phenomena (CEIDP), Toronto, ON, Canada, 16-19 October 2016; pp. 538-541.

11. Lundgaard, L.E.; Poittevin, J.; Schmidt, J.; Allen, D.; Blackburn, T.R.; Borsi, H.; Kemp, I.J. Partial discharges in transformer insulation. Cigre Task Force 2000, 15, 15-302.

12. Höhlein, I.; Kachler, A.J.; Tenbohlen, S.; Leibfried, T. Transformer life management German experience with condition assessment. Contrib. CIGRE SC12 A 2003, 2, 2-4. 
13. Wang, M.; Vandermaar, A.J.; Srivastava, K.D. Review of condition assessment of power transformers in service. IEEE Electr. Insul. Mag. 2002, 18, 12-25. [CrossRef]

14. Lokhanin, A.K.; Shneider, G.Y.; Sokolov, V.V.; Chornogotsky, V.M. Internal Insulation Failure Mechanisms of HV Equipment under Service Conditions; CIRGE: Paris, France, 2002.

15. IEC. IEC 60270:2000/AMD1:2015, High-Voltage Test Techniques_Partial Discharge Measurements; IEC: Geneva, Switzerland, 2015.

16. Hoek, S.M.; Coenen, S.; Bornowski, M.; Tenbohlen, S. Fundamental Differences of the PD Measurement according to IEC 60270 and in UHF range. In Proceedings of the 2008 International Conference on Condition Monitoring and Diagnosis, Beijing, China, 21-24 April 2008; pp. 79-81.

17. Wang, X.; Yang, M.; Yan, Z. Review and prospect of rejecting interference in Partial Discharge measurement of power equipment. Power Syst. Technol. 2000, 24, 41-45.

18. Tang, X.; Wang, W.; Zhang, X.; Wang, E.; Li, X. On-Line Analysis of Oil-Dissolved Gas in Power Transformers Using Fourier Transform Infrared Spectrometry. Energies 2018, 11, 3192. [CrossRef]

19. Chen, W.; Chen, X.; Peng, S.; Li, J. Canonical Correlation Between Partial Discharges and Gas Formation in Transformer Oil Paper Insulation. Energies 2012, 5, 1081-1097. [CrossRef]

20. Xiang, C.; Zhou, Q.; Li, J.; Huang, Q.; Song, H.; Zhang, Z. Comparison of Dissolved Gases in Mineral and Vegetable Insulating Oils under Typical Electrical and Thermal Faults. Energies 2016, 9, 312. [CrossRef]

21. Álvarez, F.; Garnacho, F.; Ortego, J.; Sánchez-Urán, M.Á. Application of HFCT and UHF Sensors in On-Line Partial Discharge Measurements for Insulation Diagnosis of High Voltage Equipment. Sensors 2015, 15, 7360-7387. [CrossRef]

22. Robles, G.; Fresno, J.M.; Martínez-Tarifa, J.M. Separation of Radio-Frequency Sources and Localization of Partial Discharges in Noisy Environments. Sensors 2015, 15, 9882-9898. [CrossRef]

23. Judd, M.D.; Cleary, G.P.; Bennoch, C.J.J. Applying UHF partial discharge detection to power transformers. IEEE Power Eng. Rev. 2002, 22, 57-59.

24. Coenen, S.; Tenbohlen, S.; Markalous, S.M.; Strehl, T. Sensitivity of UHF PD measurements in power transformers. IEEE Trans. Dielectr. Electr. Insul. 2008, 15, 1553-1558. [CrossRef]

25. Sikorski, W.; Szymczak, C.; Siodla, K.; Polak, F. Hilbert curve fractal antenna for detection and on-line monitoring of partial discharges in power transformers. Eksploatacja i Niezawodnosc 2018, 20, 343-351. [CrossRef]

26. Robles, G.; Albarracín, R.; Vázquez-Roy, J.L.; Rajo-Iglesias, E.; Martínez-Tarifa, J.M.; Rojas-Moreno, M.V.; Ardila-Rey, J. On the use of Vivaldi antennas in the detection of partial discharges. In Proceedings of the 2013 IEEE International Conference on Solid Dielectrics (ICSD), Bologna, Italy, 30 June-4 July 2013; pp. 302-305.

27. Polak, F.; Sikorski, W.; Siodla, K. Location of partial discharges sources using sensor arrays. In Proceedings of the 2014 ICHVE International Conference on High Voltage Engineering and Application, Poznan, Poland, 8-11 September 2014; pp. 1-4.

28. Kumar, A.S.; Gupta, R.P.; Udayakumar, K.; Venkatasami, A. Online partial discharge detection and location techniques for condition monitoring of power transformers: A review. In Proceedings of the 2008 International Conference on Condition Monitoring and Diagnosis, Beijing, China, 21-24 April 2008; pp. 927-931.

29. Sikorski, W.; Moranda, H.; Brodka, B.; Neumann, R. Detection, recognition and location of partial discharge sources in power transformer. Prz. Elektrotech. 2010, 86, 142-145.

30. Markalous, S.M.; Tenbohlen, S.; Feser, K. Detection and location of partial discharges in power transformers using acoustic and electromagnetic signals. IEEE Trans. Dielectr. Electr. Insul. 2008, 15, 1576-1583. [CrossRef]

31. Sikorski, W.; Siodla, K.; Moranda, H.; Ziomek, W. Location of partial discharge sources in power transformers based on advanced auscultatory technique. IEEE Trans. Dielectr. Electr. Insul. 2012, 19, 1948-1956. [CrossRef]

32. Kundu, P.; Kishore, N.K.; Sinha, A.K. A non-iterative partial discharge source location method for transformers employing acoustic emission techniques. Appl. Acoust. 2009, 70, 1378-1383. [CrossRef]

33. Lundgaard, L.E. Partial discharge. XIII. Acoustic partial discharge detection-fundamental considerations. IEEE Electr. Insul. Mag. 1992, 8, 25-31. [CrossRef]

34. Sikorski, W. Active Dielectric Window: A New Concept of Combined Acoustic Emission and Electromagnetic Partial Discharge Detector for Power Transformers. Energies 2018, 12, 115. [CrossRef]

35. Siegel, M.; Beltle, M.; Tenbohlen, S.; Coenen, S. Application of UHF sensors for PD measurement at power transformers. IEEE Trans. Dielectr. Electr. Insul. 2017, 24, 331-339. [CrossRef] 
36. Castro, B.; Clerice, G.; Ramos, C.; Andreoli, A.; Baptista, F.; Campos, F.; Ulson, J. Partial Discharge Monitoring in Power Transformers Using Low-Cost Piezoelectric Sensors. Sensors 2016, 16, 1266. [CrossRef] [PubMed]

37. Vallen, H. Acoustic Emission Testing: Fundamentals, Equipment, Applications; Castell: Wuppertal, Germany, 2006.

38. Acoustic Emission Sensors. Available online: http://www.vallen.de/fileadmin/user_upload/sov1512.pdf (accessed on 26 February 2019).

39. Differential Acoustic Emission Sensors. Available online: https://www.physicalacoustics.com/differential (accessed on 26 February 2019).

40. IEEE Guide for the Detection of Acoustic Emissions from Partial Discharges in Oil-Immersed Power Transformers; IEEE Std C57.127-2000; Institute of Electrical and Electronics Engineers: Piscataway, NJ, USA, 13 December 2000.

41. IEEE Guide for the Detection and Location of Acoustic Emissions from Partial Discharges in Oil-Immersed Power Transformers and Reactors; IEEE Std C57.127-2007 (Revision of IEEE Std C57.127-2000); Institute of Electrical and Electronics Engineers: Piscataway, NJ, USA, 31 August 2007.

42. Bengtsson, T.; Jönsson, B. Transformer PD diagnosis using acoustic emission technique. In Proceedings of the 10th International Symposium on High Voltage Engineering, Montréal, QC, Canada, 25-29 August 1997; Volume 115.

43. CIGRE Working Group. Guidelines for Unconventional Partial Discharge Measurement; CIGRE Working Group D1.33; CIGRE Working Group: London, UK, 2010.

44. CIGRE Working Group. Guidelines for Basic and Practical Aspects of Partial Discharge Detection Using Conventional (IEC60270) and Unconventional Methods; CIGRE Working Group D1.47; CIGRE Working Group: London, UK, 2015.

45. IEC-TS, PD. 62478: 2016 High Voltage Test Techniques-Measurement of Partial Discharges by Electromagnetic and Acoustic Methods; BSI: London, UK, 2016.

46. CIGRE Working Group. Partial Discharges in Transformers; CIGRE Working Group D1.29; CIGRE Working Group: London, UK, 2017.

47. Harrold, R.T. Ultrasonic spectrum signatures of under-oil corona sources. IEEE Trans. Electr. Insul. 1975, 4, 109-112. [CrossRef]

48. Harrold, R.T. Acoustic emission signatures of arcs and sparks. In Proceedings of the IEEE International Conference on Electrical Insulation, Boston, MA, USA, 9-11 June 1980; pp. 184-189.

49. Howells, E.; Norton, E.T. Detection of partial discharges in transformers using acoustic emission techniques. IEEE Trans. Power Appar. Syst. 1978, 5, 1538-1549. [CrossRef]

50. Zhu, D.; Tan, K.; Jin, X. The study of acoustic emission method for detection of partial discharge in power transformer. In Proceedings of the Second International Conference on Properties and Applications of Dielectric Materials, Beijing, China, 12-16 September 1988; pp. 614-617.

51. Bengtsson, T.; Leijon, M.; Ming, L. Acoustic frequencies emitted by partial discharges in oil. In Proceedings of the 8th International Symposium on High Voltage Engineering, Yokohama, Japan, 23-27 August 1993; pp. 113-116.

52. Scholey, T.; Gorgius, D. Ultrasonic detection of discharges in power transformers. In Proceedings of the 9th International Symposium on HV Engineering, Graz, Austria, 28 August-1 September 1995.

53. Sakoda, T.; Arita, T.; Nieda, H.; Ando, K.; Otsub, M.; Honda, C. Studies of elastic waves caused by corona discharges in oil. IEEE Trans. Dielectr. Electr. Insul. 1999, 6, 825-830. [CrossRef]

54. Boczar, T. Identification of a specific type of PD from acoustic emission frequency spectra. IEEE Trans. Dielectr. Electr. Insul. 2001, 8, 598-606. [CrossRef]

55. Kundu, P.; Kishore, N.K.; Sinha, A.K. Frequency domain analysis of acoustic emission signals for classification of partial discharges. In Proceedings of the 2007 Annual Report-Conference on Electrical Insulation and Dielectric Phenomena, Vancouver, BC, Canada, 14-17 October 2007; pp. 146-149.

56. Sikorski, W.; Ziomek, W. Detection, recognition and location of partial discharge sources using acoustic emission method. In Acoustic Emission; Intech Open: Rijeka, Croatia, 2012.

57. Sokolov, V.; Mayakov, V.; Kuchinsky, G.; Golubev, A. On-Site Partial Discharge Measurement of Transformers. Available online: http://es.eaton.com/InsulGardSalesTool/Documentation/PD\%20Transformer. pdf (accessed on 18 April 2019).

58. Sokolov, V. Power Transformer: Post Failure and Post Mortem Analysis. In Proceedings of the My Transfo, Rio de Janeiro, Brazil, 7-9 March 2007. 
59. Sokolov, V. Understanding failure modes of transformers. In Proceedings of the Euro TechCon 2005, Chester, UK, 28-30 November 2005; pp. 43-65.

60. Mitchinson, P.M.; Lewin, P.L.; Strawbridge, B.D.; Jarman, P. Tracking and surface discharge at the oil-pressboard interface. IEEE Electr. Insul. Mag. 2010, 26, 35-41. [CrossRef]

61. Li, J.; Si, W.; Yao, X.; Li, Y. Partial discharge characteristics over differently aged oil/pressboard interfaces. IEEE Trans. Dielectr. Electr. Insul. 2009, 16, 1640-1647. [CrossRef]

62. Sokolov, V.; Berler, Z.; Rashkes, V. Effective methods of assessment of insulation system conditions in power transformers: A view based on practical experience. In Proceedings of the Electrical Insulation Conference and Electrical Manufacturing and Coil Winding Conference (Cat. No. 99CH37035), Cincinnati, OH, USA, 26-28 October 1999; pp. 659-667.

63. Sikorski, W.; Walczak, K.; Przybylek, P. Moisture migration in an oil-paper insulation system in relation to online partial discharge monitoring of power transformers. Energies 2016, 9, 1082. [CrossRef]

64. Sokolov, V.; Vanin, B. Evaluation of power transformer insulation through measurement of dielectric characteristics. In Proceedings of the 63rd Annual International Conference Doble Clients, Boston, MA, USA, 25-29 March 1996.

65. Gao, B.; Yu, R.; Hu, G.; Liu, C.; Zhuang, X.; Zhou, P. Development Processes of Surface Trucking and Partial Discharge of Pressboards Immersed in Mineral Oil: Effect of Tip Curvatures. Energies 2019, 12, 554. [CrossRef]

66. Li, F.; Cheng, Y.; Tian, X.; Duan, B.; Cheng, C.; Zhao, Z. Relationship between carbonized traces and space charges in oil-paper insulation. In Proceedings of the 2015 IEEE 11th International Conference on the Properties and Applications of Dielectric Materials (ICPADM), Sydney, NSW, Australia, 19-22 July 2015; pp. 971-974.

67. Piotrowski, T.; Rozga, P.; Kozak, R. Analysis of excessive hydrogen generation in transformers in service. IEEE Trans. Dielectr. Electr. Insul. 2015, 22, 3600-3607. [CrossRef]

68. Asokan, T.; Bandaru, S. X-wax formation in transformer liquid dielectrics. In Proceedings of the IEEE International Conference on Dielectric Liquids (ICDL 2005), Coimbra, Portugal, 26 June-1 July 2005; pp. 401-404.

69. Lokhanin, A.K.; Shneider, G.Y.; Sokolov, V.; Chornogotsky, V.M.; Morozova, T.I. Internal insulation failure mechanisms of HV equipment under service conditions. Cigre Rep. 15 2002, 201, 1-6.

70. Przybylek, P. Investigations of the Temperature of Bubble Effect Initiation in Oil-Paper Insulation. Prz. Elektrotech. 2010, 86, 166-169.

71. Heinrichs, F.W. Bubble formation in power transformer windings at overload temperatures. IEEE Trans. Power Appar. Syst. 1979, 5, 1576-1582. [CrossRef]

72. Nakao, Y.; Itoh, H.; Sakai, Y.; Tagashira, H. Studies of impulse creepage discharge in transformer oil. IEEE Trans. Electr. Insul. 1991, 26, 732-738. [CrossRef]

73. Zainuddin, H.; Mitchinson, P.M.; Lewin, P.L. Investigation on the surface discharge phenomenon at the oil-pressboard interface. In Proceedings of the 2011 IEEE International Conference on Dielectric Liquids, Trondheim, Norway, 26-30 June 2011; pp. 1-4.

74. Ziomek, W.; Kuffel, E.; Sikorski, W.; Staniek, P.; Siodła, K. Location and recognition of partial discharge sources in a power transformer using advanced acoustic emission method. Prz. Elektrotech. 2008, 84, $20-23$.

75. Ding, H.-Z.; Wang, Z.D.; Jarman, P. On electric stresses at wedge-shaped oil gaps in power transformers with application to surface discharge and breakdown. In Proceedings of the 2008 IEEE International Conference on Dielectric Liquids, Futuroscope-Chasseneuil, France, 30 June-3 July 2008; pp. 1-4.

76. Sikorski, W. The detection and identification of partial discharges in power transformer with the use of the acoustic emission method. Prz. Elektrotech. 2010, 86, 229-232.

77. Forouharmajd, F.; Mohammadi, Z.; Ahmadvand, M. Sound pressure level tools design used in occupational health by means of Labview software. Int. J. Environ. Health Eng. 2015, 4, 41.

78. De Silva, C.W. (Ed.) Vibration Monitoring, Testing, and Instrumentation; CRC Press: Boca Raton FL, SUA, 2007.

79. Krimholtz, R.; Leedom, D.A.; Matthaei, G.L. New equivalent circuits for elementary piezoelectric transducers. Electron. Lett. 1970, 6, 398-399. [CrossRef]

80. Bechmann, R.; Fair, I.E. Standard definitions and methods of measurement for piezoelectric vibrators. IEEE ANSI 1970, 176, 1-12. 
81. Mason, W.P. Electromechanical Transducers and Wave Filters, 2nd ed.; Van Nostrand: Princeton, NJ, USA, 1948; ISBN 9780442051648.

82. Redwood, M. Transient performance of a piezoelectric transducer. J. Acoust. Soc. Am. 1961, 33, 527-536. [CrossRef]

83. Merks, E.J.; Bouakaz, A.; Bom, N.; Lancee, C.T.; Van Der Steen, A.F.; De Jong, N. Design of a multilayer transducer for acoustic bladder volume assessment. IEEE Trans. Ultrason. Ferroelectr. Freq. Control 2006, 53, 1730-1738. [CrossRef]

84. Tran-Huu-Hue, L.P.; Desmare, R.; Lavassort, F.; Lethiecq, M. KLM circuit-based method for modeling multilayer piezoelectric structures. In Proceedings of the 1997 IEEE Ultrasonics Symposium Proceedings. An International Symposium (Cat. No. 97CH36118), Toronto, ON, Canada, 5-8 October 1997; pp. 995-998.

85. Oakley, C.G. Calculation of ultrasonic transducer signal-to-noise ratios using the KLM model. IEEE Trans. Ultrason. Ferroelectr. Freq. Control 1997, 44, 1018-1026. [CrossRef]

86. Martin, P.M.; Good, M.S.; Johnston, J.W.; Posakony, G.J.; Bond, L.J.; Crawford, S.L. Piezoelectric films for 100-MHz ultrasonic transducers. Thin Solid Film. 2000, 379, 253-258. [CrossRef]

87. Castillo, M.; Acevedo, P.; Moreno, E. KLM model for lossy piezoelectric transducers. Ultrasonics 2003, 41, 671-679. [CrossRef]

88. ASTM E976-10 Standard Guide for Determining the Reproducibility of Acoustic Emission Sensor Response; ASTM International: West Conshohocken, PA, USA, 2016; p. 7.

(C) 2019 by the author. Licensee MDPI, Basel, Switzerland. This article is an open access article distributed under the terms and conditions of the Creative Commons Attribution (CC BY) license (http://creativecommons.org/licenses/by/4.0/). 